
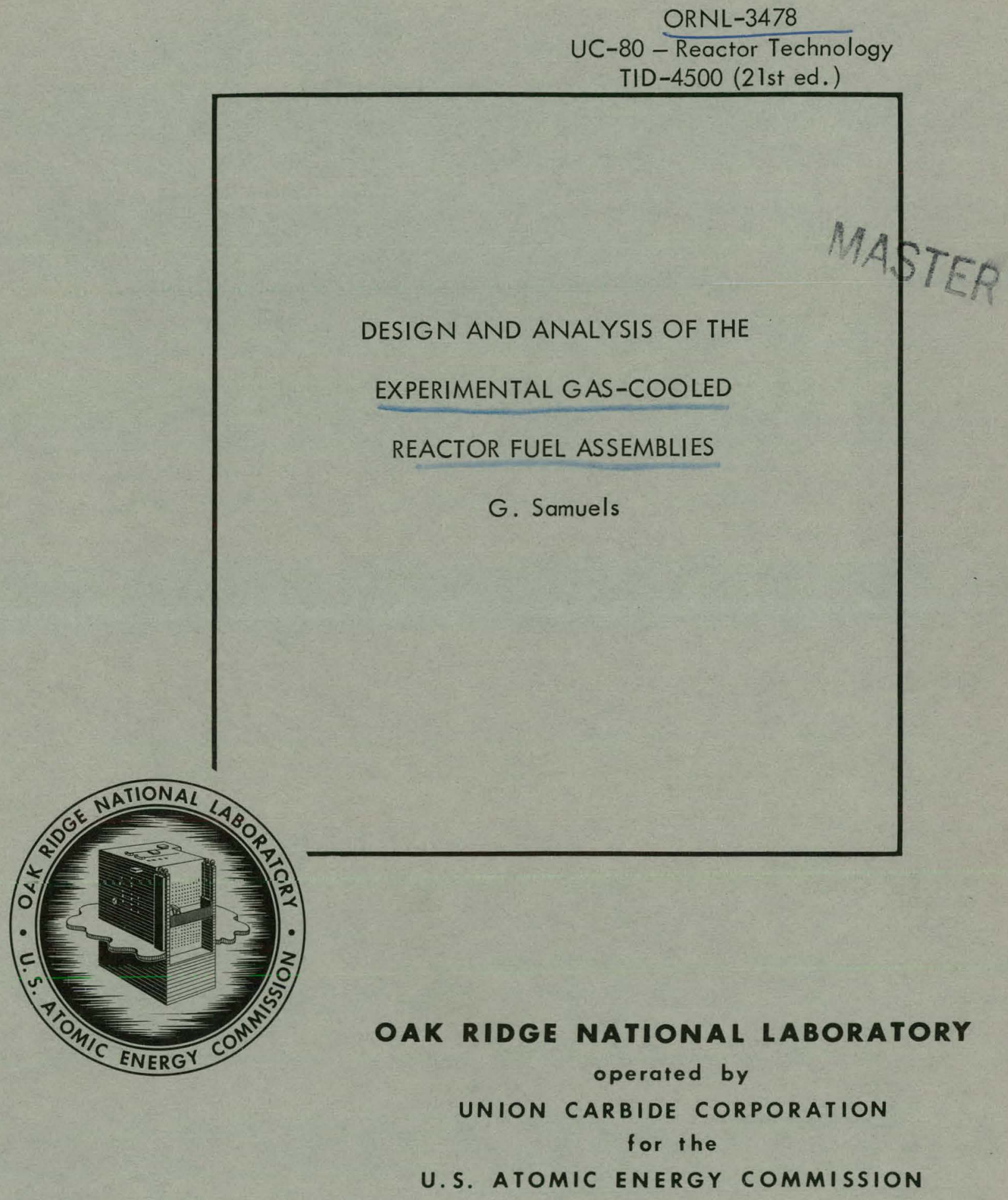


\section{DISCLAIMER}

This report was prepared as an account of work sponsored by an agency of the United States Government. Neither the United States Government nor any agency Thereof, nor any of their employees, makes any warranty, express or implied, or assumes any legal liability or responsibility for the accuracy, completeness, or usefulness of any information, apparatus, product, or process disclosed, or represents that its use would not infringe privately owned rights. Reference herein to any specific commercial product, process, or service by trade name, trademark, manufacturer, or otherwise does not necessarily constitute or imply its endorsement, recommendation, or favoring by the United States Government or any agency thereof. The views and opinions of authors expressed herein do not necessarily state or reflect those of the United States Government or any agency thereof. 


\section{DISCLAIMER}

Portions of this document may be illegible in electronic image products. Images are produced from the best available original document. 


\section{Printed in USA. Price: $\$ 1.25$ Available from the}

Office of Technical Services

U. S. Dopartment of Commerce

Washington 25 , D. C.

\section{LEGAL NOTICE}

This report was prepared as an account of Government sponsored work. Neither the United States, nor the Commission, nor any person acting on behalf of the Commission:

A. Makes any warranty or representation, expressed or implied, with respect to the accuracy, completeness, or usefulness of the information contained in this report, or that the use of any information, apparatus, method, or process disclosed in this report may not infringe privately owned rights; or

B. Assumes any liabilities with respect to the use of, or for damages resulting from the use of any information, apparatus, method, or process disclosed in this report.

As used in the above, "person acting on behalf of the Commission" includes any employee or contractor of the Commission, or employee of such contractor, to the extent that such employee or contractor of the Commission, or employee of such contractor prepares, disseminates, or provides access to, any information pursuant to his employment or contract with the Commission, or his employment with such contractor. 
Contract No. W-7405-eng-26

Reactor Division

DESIGN AND ANALYSIS OF THE EXPERIMENTAL GASCOOLED REACTOR FUEL ASSEMBLTES

G. Samuels

\author{
- Date Issued
}

SEP 2: 190.

OAK RIDGE NATIONAL LABORATORY Oak Ridge, Tennessee operated by UNION CARBIDE CORPORATION for the U.S. ATOMIC ENERGY COMMISSION 


\section{THIS PAGE}

\section{WAS INTENTIONALLY \\ LEFT BLANK}


CONTENTS

Page

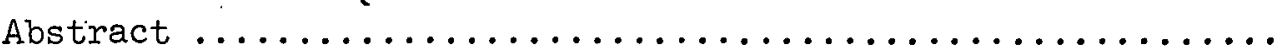

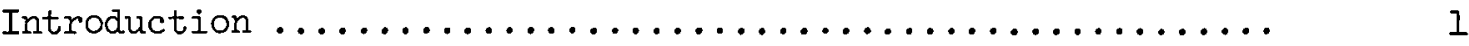

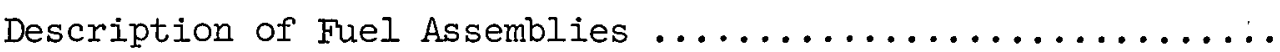

Experimental Studies of Heat Transfer, Fluid Flow, and Mechanical Properties ......................... 10

Correlation of Heat Transfer and Mixing Data ............. 15

Thermal Analysis of Fuel Elements .................. 22

Fuel Element Hot-Channel Factors $\ldots \ldots \ldots \ldots \ldots \ldots \ldots \ldots \ldots \ldots \ldots$

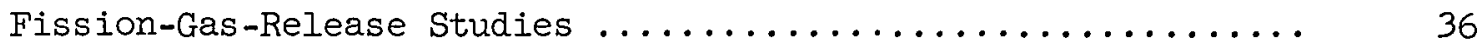

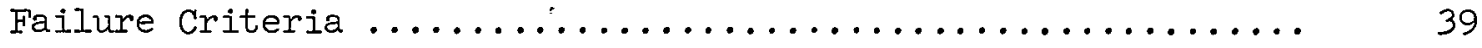

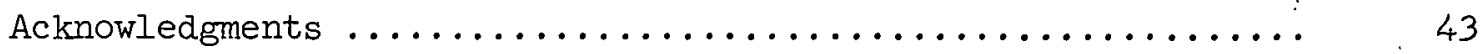

References ................................. 44 


\title{
DESIGN AND ANALYSIS OF THE EXPERTMENTAL GAS- COOLED REACTOR FUEL ASSEMBLIES
}

\author{
G. Samuels
}

$\because \cdots$

Abstract

The design of the Experimental Gas-Cooled Reactor fuel assemblies is described and a brief outline of the experimenlial heal linduser dul rluid dyuamie stulies and mechamieal testing is given. Correlations derived from the experimental data are given, and the results of their application to the fuel elemenl analys is are shown. The failure criteria are presented, the hot-channel factors are described, and the expected fission-gas pressure buildup within the elements is discussed.

\section{Introduction}

The Experimental Gas-Cooled Reactor (EGCR) is a combined experimental and power demonstration reactor now under construction at Oak Ridge, Tennessee; it is scheduled for operation in late 1964. It will be fueled with enriched uranium dioxide clad in stainless steel; the fuel will be moderated with graphite and cooled with helium. The plant is designed to produce $85-\mathrm{Mw}$ thermal and $22-\mathrm{Mw}$ electrical power, with a reactor coolant outlet temperature of $1043^{\circ} \mathrm{F}$, a system pressure of $315 \mathrm{psia}$, and a coolant flow rate of $427,000 \mathrm{lb} / \mathrm{hr}$.

The reactor core is a vertical cylinder $15 \mathrm{ft} 10 \mathrm{in}$. in diameter and $19 \mathrm{ft} 4 \mathrm{in}$. high, with an active region that is $11 \mathrm{ft} 10 \mathrm{in}$. in diameter and $14 \mathrm{ft} 6 \mathrm{in}$. high. The core is constructed of monolithic graphite columns 16 by $16 \mathrm{in.}$ square and $19 \mathrm{ft} 4 \mathrm{in}$. long. Each column contains four 5.25-in. holes on 8-in. centers to accommodate the fuel assemblies. There is a total of 232 fuel channels, and provisions have been made for eight through-tubes for experimental loops. Each of the 232 fuel channels contains six assemblies and a top and bottom dummy assembly.

The fuel. assemblies for the EGCR are a seven-element cluster of stainless-steel-clad, corcd, $\mathrm{UO}_{2}$ pellets. The basic concept for the 
design of these assemblies was essentially the same as that used for the GCR-II study. ${ }^{1-3}$ The engineering problems and the research and development effort required to provide design information for such a fuel concept were delineated in considerable detail at the time of the GCR-II study. 2,3

In late 1958 and in 1959, experimental programs were initiated for developing the necessary design and materials properties data. These programs were of four major types: (I) heat transfer, fluid flow, and mechanical properties testing, (2) development of materials and fabrication techniques, (3) irradiation testing of materials, and (4) postirradiation examination of materials. This report is concerned with the design of the assemblies and with analysis of the data obtained in the heat transfer, fluid flow, and mechanical property tests.

\section{Description of Fuel Assemblies}

A fuel assembly for the EGCR consists of a seven-element cluster of $\mathrm{UO}_{2}$ pellets clad with 0.020 -in. -thick type 304 stainless stieel. The cluster is supported within a l-in.-thick graphite sleeve (Fig. 1) that has an outside diameter of 5 in., an inside diameter of 3 in., and a stacked length of $29 \mathrm{in.}$ Since the graphite sleeves fit loosely in the moderator, there may be some smail angular misalignment between stacked assemblies. The ends of the sleeves are therefore shaped to effect a ball-and-socket type of seat in order to prevent this misalignment from allowing leakage from the inside of the sleeve to the annulus between the sleeve and moderator. The shape of the top end is conical and the bottom end spherical.

The design of the top and bottom spiders that position the fuel elements was influenced by both flow considerations and fuel-handling procedures for the reactor. The normal method of charging or discharging fuel is from the bottom, and the machine provided for this purpose is designed to carry out its functions during operation of the reactor at full pressure and full power. A service machine, located at the top of the reactor, may also be used to both load and unload fuel assemblies under abnormal or special conditions. Fuel handling by the service 


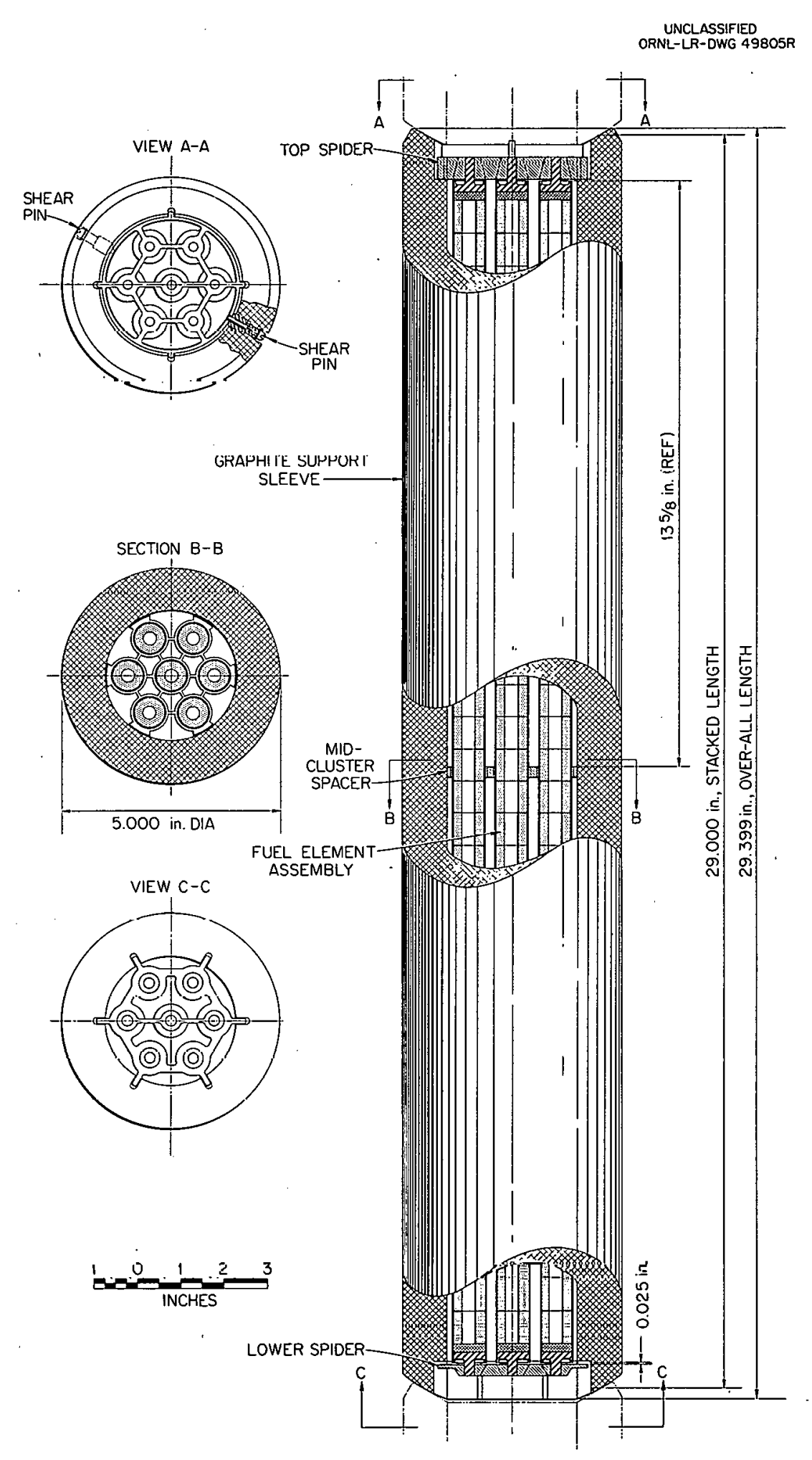

Fig. 1. EGCR Fuel Assembly. 
machine is much slower than by the charge machine, but, as with the charge machine, the operation may be carried out at full power. This dual handling scheme required that the fuel assemblies be designed for either top or bottom charging. One item of concern is the possibility of a graphite sleeve becoming "jammed" in a channel so that the fuel assembly cannot be removed by normal handling procedures from either the top or bottom. To facilitate removal of such an assembly, two shear pins are incorporated at the top of each assembly to fasten the cluster to the sleeve, and the thickness of the centering tabs of the bottom spider is only $0.050 \mathrm{in.} \mathrm{thick.} \mathrm{In} \mathrm{the} \mathrm{event} \mathrm{that} \mathrm{an} \mathrm{assembly} \mathrm{becomes} \mathrm{"jammed"}$ in a channel, the reactor will be shut down and a special grapple will be used to shear the two pins. After the pins are sheared the bottom tabs will bend downward so that the stainless steel fuel bearing part of the assembly can be lifted out. This will then allow space for other special tools to be used to remove the sleeve. The pins are sized so that the force required to shear them at room temperature is $900 \mathrm{lb}$. The tabs on the bottom spider will fold downward under a load of 275 l.b. The design of the pins and tabs is such that no pieces are free to fall. into the system during this operation.

Since the number of access nozzles in the top or bottom of the reactor vessel is considerably less than the number of fuel shannels in the core, it was necessary that the length of the fuel assembly be limited to facilitate its passage through a curved guide tube at the bottom of the core or its horizontal movement at the top of the reactor. These considerations ruled out the use of a rigid 14.5-ft-long assembly in which the clusters could be oriented with respect to each other before insertion into the core. Neither fuel-handling machine can angularly index the shorter assemblies, and thus there is random angular orientation of an assembly relative to the one above or below. Therefore the spiders had to be designed to assure an adequately uniform flow distribution through the clusters regardless of alignment.

The top spider serves to support the cluster in the sleeve and also to locate the individual elements relative to one another and to the sleeve. The spiders are centered in the sleeves by radial tabs that fit 
into radial slots in the sleeves. This design was dictated by the large difference between the coefficients of expansion of stainless steel and graphite. Since the temperatures of the spiders and sleeves will vary from 500 to about $1100^{\circ} \mathrm{F}$ along a channel, any close fit between the two materials must be limited to parts with small dimensions. With the design shown in Fig. 1, the allowance for differential expansion had to be made only for the thickness of the tabs and slots, and very close centering of the cluster in the sleeve was possible.

The bottom spider does not carry any load, except a side reaction caused by temperature gradients in the cluster that cause bowing of the rods. Only three of the seven rods, the alternate outer rods, are welded to the bottom spider. The offset of the centering bar between the outer bosses on the bottom spider is used to force flow to the center element and to induce flow mixing in the outer part of the assembly:

One of the six outer elements is shown in Fig. 2. The outer elements differ from the inner element only in the design of the spacer. The spacer for the central element is a thin ring that does not have the pad or the two protruding tabs. Each of the elements contains 36, cored, 0.707-in.-OD, 0.323-in.-ID UO 2 pellets about 0.75 in. long. There is also an $\mathrm{MgO}$ pellet $3 / 16$ in. long at each end of the $\mathrm{UO}_{2}$ column to protect the stainless steel end caps from the high central $\mathrm{UO}_{2}$ temperatures. The end caps are pressed into and welded to the cladding. The primary purpose of the spacer is to prevent bowing of the rods due to thermal gradients within the cluster, and it thus adds thermal stability to the assembly. The configuration of the spacer was dictated by both vibration and flow considerations. The pad between the outer elements and the sleeve provides a large bearing surface between the graphite and steel and reduces the possibility of damage to the sleeve by vibrations. The large pad also serves two additional purposes: (1) by blocking part of the area in the outer H'Lw area of the cluster, it prevents the inner spacers from forcing flow out of the inner area around the central element where the gas temperature will be highest, and (2) it induces some turbulence and mixing in the region between the outer elements and the sleeve and reduces the temperature gradients within the gas in these 
UNCLASSIFIED

ORNL-LR-DWG 51647

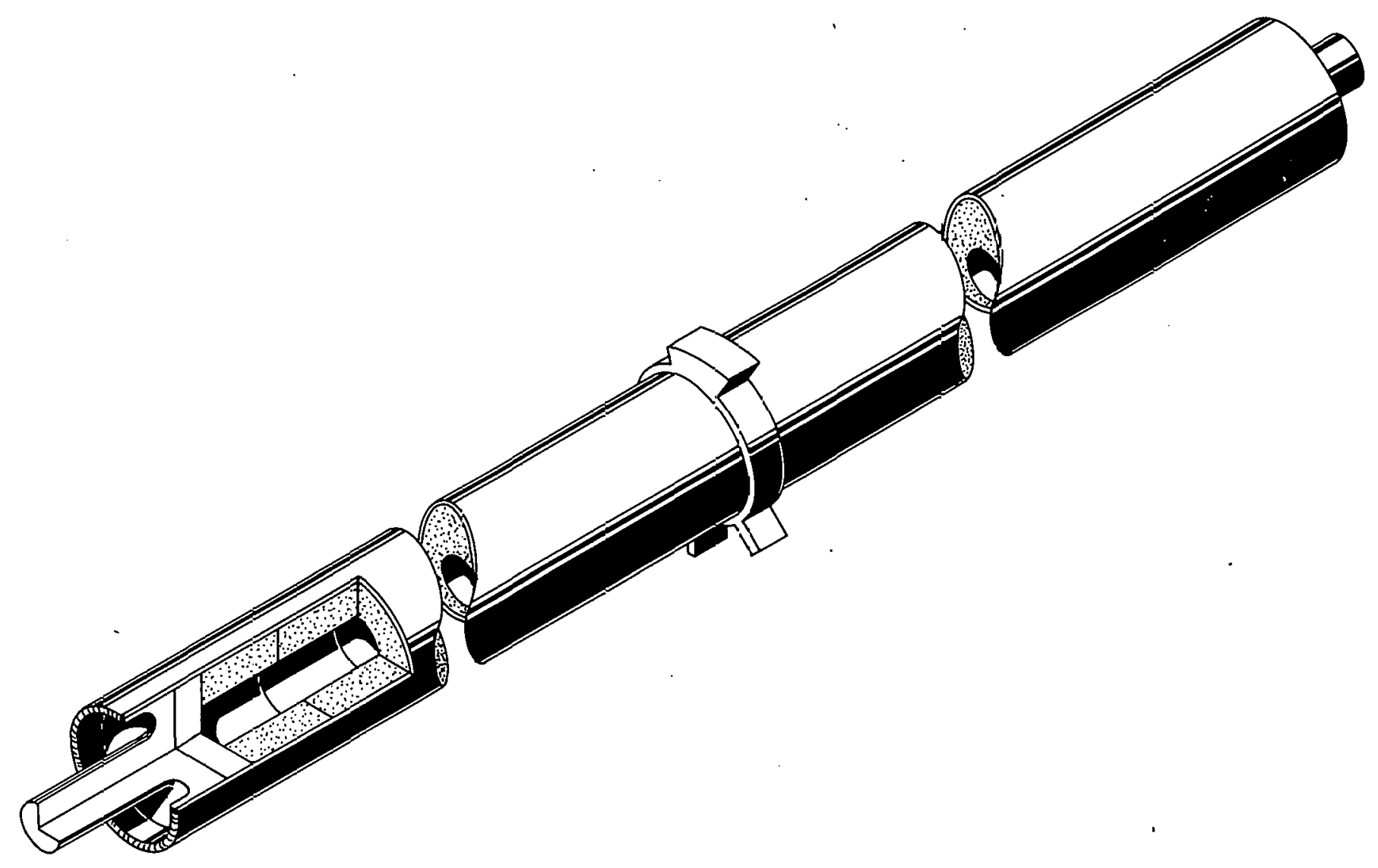

a

Fig. 2. Friel Element. 
regions. Without some form of mixing, the temperature of the gas midway between the outer elements and along the sleeve would be much lower than the average temperature across the channel.

One of the $\mathrm{UO}_{2}$ pellets is shown in Fig. 3. The nominal clearance between the pellets and the cladding is 0.004 in., and the tolerance on both the inside diameter of the cladding and the outside diameter of the pellet is 0.001 in.; thus the variation in diametral clearance will be from 0.002 to 0.006 in. These tight tolerances are necessary to prevent the formation of wrinkles in the cladding in the high-temperature region of the reactor where the cladding creeps and collapses onto the $\mathrm{UO}_{2}$. The small clearance will also reduce the temperature and therefore the fission-product release rate in the areas of the reactor where the cladding is not subject to creep. It has been found that the 0.002-in. minimum clearance is necessary to assure easy loading of the pellets into. the tube.

The hollow center in the $\mathrm{UO}_{2}$ fuel pellets serves to reduce the fission-gas-pressure buildup within the elements. For a given heat flux from an element, the removal of the central cores of the pellets reduces the temperature and therefore the fractional release of the fission products. The $\mathrm{UO}_{2}$ removed leaves a storage volume for the fission products that are released. This volume, although very inefficient because of its high temperature, is sufficient to prevent the pressure within the elements from exceeding the external coolant pressure of 300 psia for the design Iife of $10,000 \mathrm{Mwd} / \mathrm{MI}^{\mathrm{I}}$.

As shown in Fig. 3, the ends of the pellets are dished or chamfered to allow for axial expansion of the pellets in the higher power regions of the core. The heat generation rate along a channel may vary as much as 40 to 1 . Under these conditions, the peak heat flux in the highest power channel will be $173,000 \mathrm{Btu} / \mathrm{hr} \cdot \mathrm{ft}^{2}$ at a point one-third of the core length from the bottom of the reactor. 'l'he average $f^{\prime} l u x$ in the top assembly in this channel will be about $4000 \mathrm{Btu} / \mathrm{hr} \cdot \mathrm{ft}^{2}$. The axial coolant temperature variation for this case is such that, at the highest flux point, the temperature will be about $850^{\circ} \mathrm{F}$ and, in the top assembly, the temperature will be $1075^{\circ} \mathrm{F}$. For these conditions the expansion of 


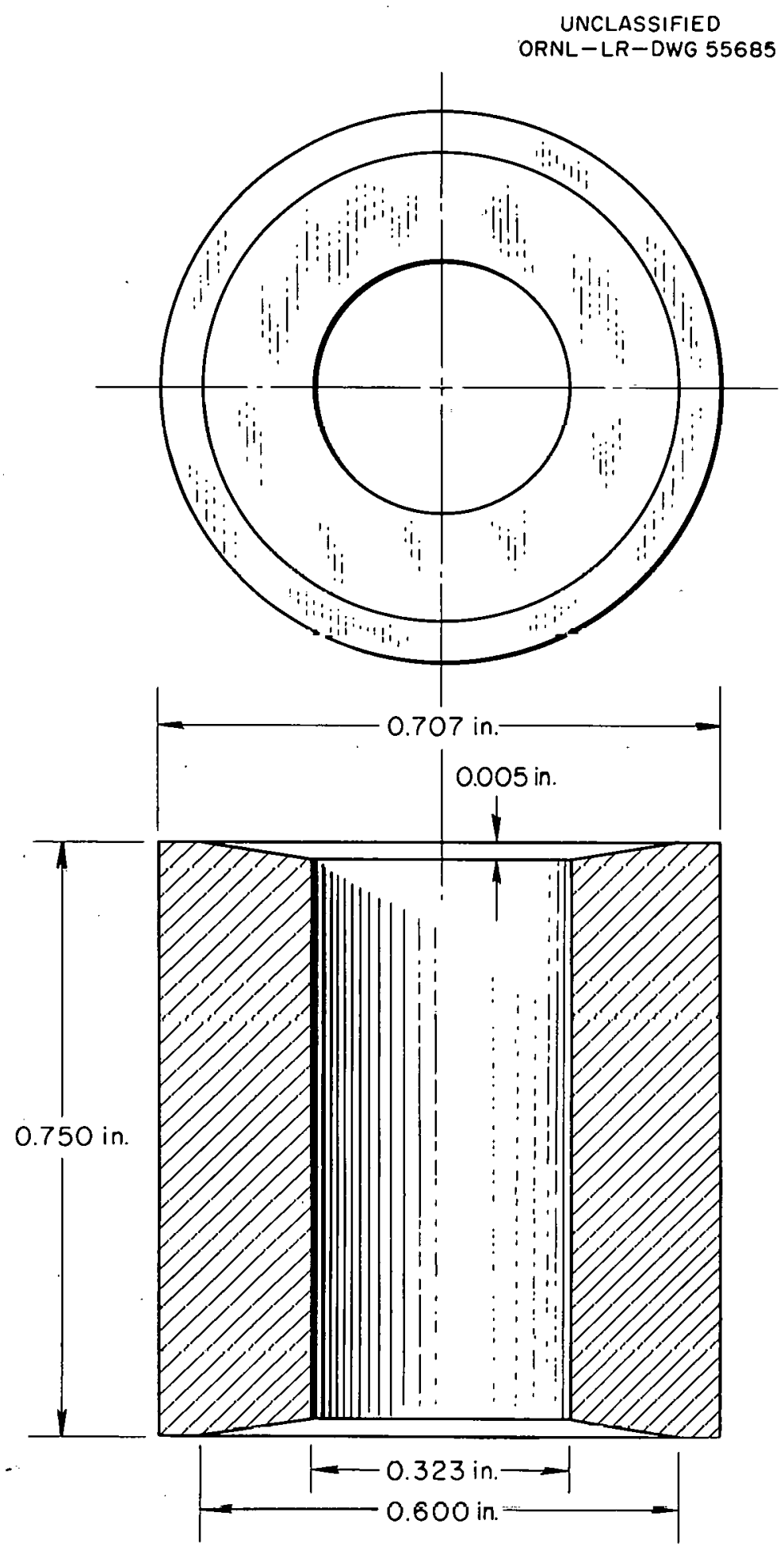

Fig. 3. Fuel Pellet Sketch. 
the pellets will be greater than that of the cladding at the peak flux point and less than that of the cladding in the top assembly. If a clearance were left at the top of the pellet column to allow for differential expansion, this clearance in the upper assemblies would become larger and might lead to collapse of the unsupported length of cladding into the gap. Since the upper and lower three assemblies will be interchanged at their mid-life, any circumference wrinkle into the gap would eliminate the original clearance and result in an axial strain on the cladding. The results of tests ${ }^{4}$ to investigate the behavior of a column of clad pellets have shown that for square end pellets the axial growth depends on the central temperature of the pellets and that by dishing the pellets the axial growth is reduced. The use of the dished pellets then allows for the differential growth in the highest power region of the core where the central temperature and therefore axial expansion is greatest, and no additional "head room" at the top of the element is necessary. As the central and outer temperatures of the pellets in the lowest flux regions are very nearly the same, the effect of the dished ends on the relative growth is nil. The elimination of the initial clearance reduces the size of the end gap in the upper assemblies and no wrinkle is formed. The nominal depth of the chamfer at the inner surface of the pellet is 0.005 in., and the outside diameter of the chamfer is 0.600 in.

The bottom dummy assemhly serves several purposes; it decreases neutron streaming from the channels, positions and supports the column of . fueled assemblies, and contains both fixed and variable orifices to control the coolant flow through the core. The variable orifice may be adjusted at full power operation to control the exit gas temperature from each channel. The top dummy also decreases neutron streaming from the channels and serves as a "hnld-rnw" mechanism to prevent the fuel assemblies from "floating" into the top plenum of the reactor. Under normal operation the weight of the assemblies is sufticient to overcome the lifting force of the coolant, but in the event of maloperation during fuel handling or a loss of pressure due to rupture of the primary coolant system, additional restraint may be required. 
Experimental Studies of Heat Transfer, Fluid Flow, and Mechanical Properties

In the design of the fuel elements it was necessary to consider the local temperatures within the cluster and the effect of temperature asymmetries on the thermal stability of the cluster. In order to determine the temperature structure within a cluster, detailed knowledge of the local heat generation rates, heat transfer coefficients, and gas temperature is needed. Since the design data required for determining the local heat transfer coefficients and gas temperatures were nonexistent, a rather extensive series of heat transfer and fluid flow experiments was conducted to develop this information. The four types of experiments carried out included (1) heat transfex and pressure drop measurements, (2) mass transfer tests, (3) gas velocity distribution measurements, and (4) gas mixing studies. The heat transfer and mass transfer tests were made primarily to determine the variation in the coefficient about each of the seven elements and also to determine the effect of the length-to-equivalent diameter on the coefficient. The results of the velocity distributlun measurements and gas mixing studies were used to determine the gas temperature variations throughout the passages within the cluster.

Heat transfer tests were conducted at ORNL and Allis-Chalmers.* The techniques used in both ot these studies were quite similar in that electrical heating of 0.020-in.-wall stainless steel tubes was used to simulate the heat generation in the elements. The coolant was air at atmospheric pressure, and the maximum heat flux was about $700 \cap \mathrm{Btu} / \mathrm{hr} \cdot \mathrm{ft}{ }^{2} \cdot{ }^{\circ} \mathrm{F}$ or about 10\% of the average heat flux for the reastor. Fnr equal Rejmnlds numbers, air at atmospheric pressure and a heat flux of $7000 \mathrm{Btu} / \mathrm{hr} \cdot \mathrm{ft}^{2} \cdot{ }^{\circ} \mathrm{F}$ gives the same film temperature drop and rate of rise of gas temperature as helium at $300 \mathrm{psia}$ and the average reactor heat flux. The temperatures of the elements were measured with both fixed thermocouples and a sliding contact thermocouple inserted down the center of the tubes. This latter type of measurement provides data with which to make a detailed plot of the circumferential and axial temperature variations in the tubes.

*Allis-Chalmers Manufacturing Co., Atomic Energy Division, Nuclear Power Department. 
One difficulty with both of these test systems was that only one assembly could be tested, and therefore the effect of various angular alignments of the fuel assemblies could not be checked. In addition, the spiders could not be duplicated in the electrically heated systems because of insulating problems. In order to offset these difficulties and the fact that the conduction and radiation in the tests had a large effect on the computed local coefficients, a series of isothermal mass transfer tests was run at ORNL. The tests were made for a number of tube spacings, with the final series on the exact EGCR design geometry. In these final tests, two assemblies were placed in series in such a manner that the relative angular orientation could be varied to determine its effect on local coefficients. These tests utilized solid aluminum rods for the elements, with one rod undercut and coated with naphthalene and then remachined to its original diameter. The rods were measured both before and after testing with a profilometer to determine the mass removed, and the data were then used to determine the local " $j$ " factors. $5-7$ The fluid dynamics experiments were conducted at ORNL and were of two types: velocity distribution 8,9 and mixing studies. The velocity distributions were determined by pitot tube traverses across the cluster at a number of length-to-equivalent diameter locations along the cluster. The measurements were made at distances of $0.050,0.100,0.150,0.200$, $0.250,0.300,0.400$, and $0.500 \mathrm{in}$. from the walls of the tubes and at intervals of $20^{\circ}$ around the tubes. These measurements were made for several relative angular rotations between two assemblies in series, with the measurements made on the second assembly. The pitot tubes measured only the axial component of the velocity. An example of the velocity distribution near the entrance of an assembly (length-to-equivalent diameter, $\mathrm{L} / \mathrm{d}_{e}$, ratio of 3.9 ) with zero degrees angular rotation is shown in Fig. 4 . The final piece of information required for determining the gas and surface temperatures in a cluster is the degree of mixing between the different flow areas. This mixing may be of two types, that is, that resulting from velocity shifts caused by flow obstructions, such as the top and bottom spiders, and that resulting from the normal turbulence in the fluwing gas or lhe eddy diffusivity. The method of studying these 


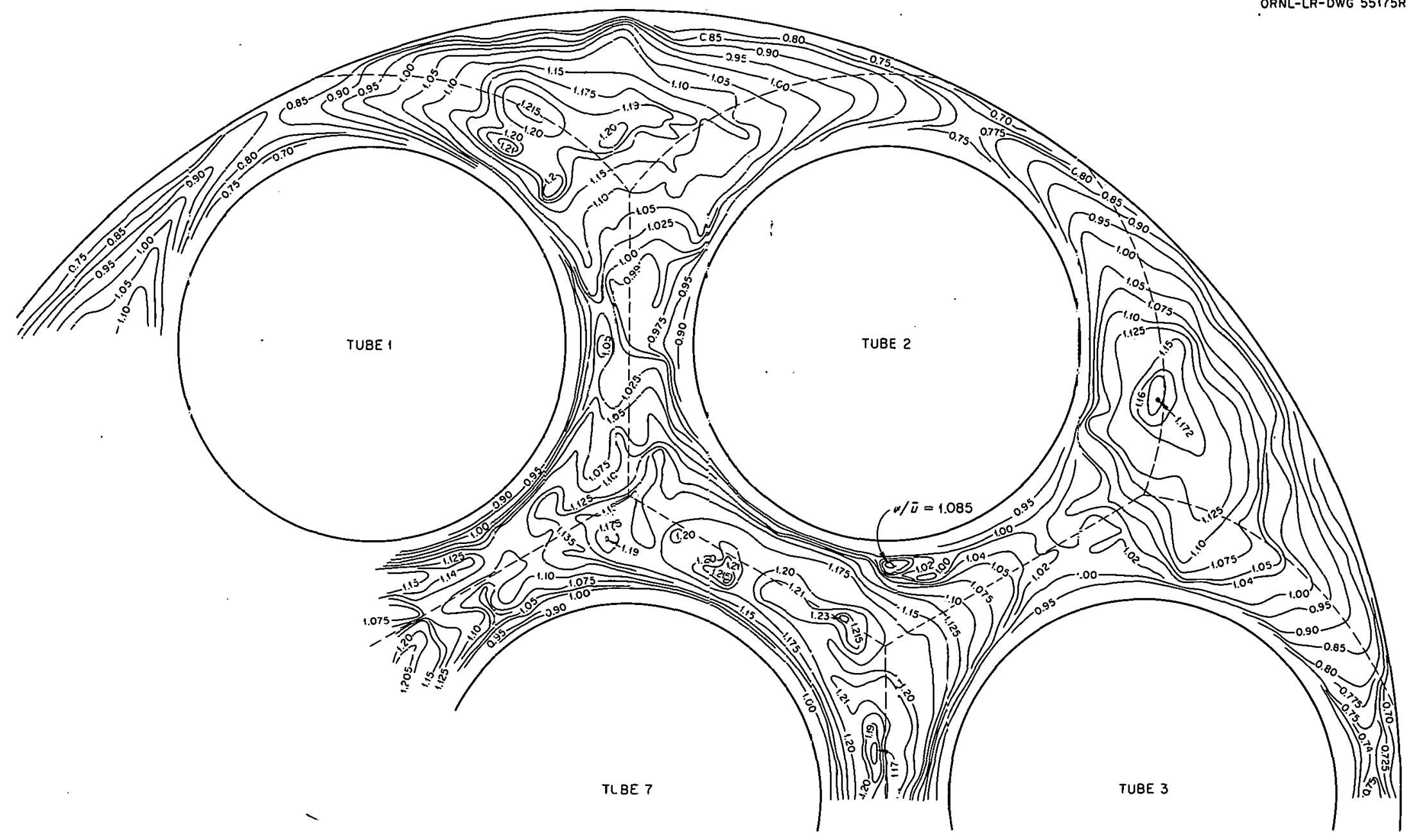

Fig. 4. Velocity Profile in Seven-Element Ciuster at $\mathrm{L} / \mathrm{d}_{\mathrm{e}}=3.9$ for 0-deg Angular Orientation. 
factors was to introduce a second gas (helium) into air flowing through the cluster. The concentration of the helium at various downstream positions was determined with a thermal-conductivity comparison cell. Since the static diffusion of helium in air is very small compared with the eddy diffusivity of the turbulent stream, the dispersion of the helium gave a measurement of the diffusivity of the stream.

In addition, tests were conducted to determine the amplitude of the vibration of the elements and to determine the strength of the assemblies under static and dynamic loads. The vibrations were measured by optıcal means using a glass wall around the cluster. The maximum amplitude found was about 0.0015 in. This element was an outer element of the cluster, and its midpoint spacer was not in contact with either other elements or the glass wall. Since the elements in the reactor will be subjected to thermal gradients which will cause them to bow, the elements will have lateral deflections that will force contact between the spacers and the graphite wall. This center contact will reduce the vibration in the reactor.

The mechanical tests of the fuel assemblies for determining the static and dynamic loads that the assemblies can withstand were conducted by Allis-Chalmers. ${ }^{10}$ These studies included tests for determin-. ing the maximum allowable static compression Load tor an assembly and also the effect of impact loads obtained by dropping the assemblies onto an "anvil" and onto one another from various heights at both room temperatuire and at $1100^{\circ} \mathrm{F}$.

The heat generation rates were determined by both analytical ${ }^{11,12}$ and experimental means, and the results are shown in Figs. 5, 6, and 7 . Figure 5 shows the variation in the heat generation across a channel as a result of the self-shielding of the fuel; Fig. 6 shows the flux peaking at the end of the assemblies; and Fig. 7 shows the mean heat generation rates along the highest power channel in the core. The latter figure does not include the peaking at the end of each assembly. 


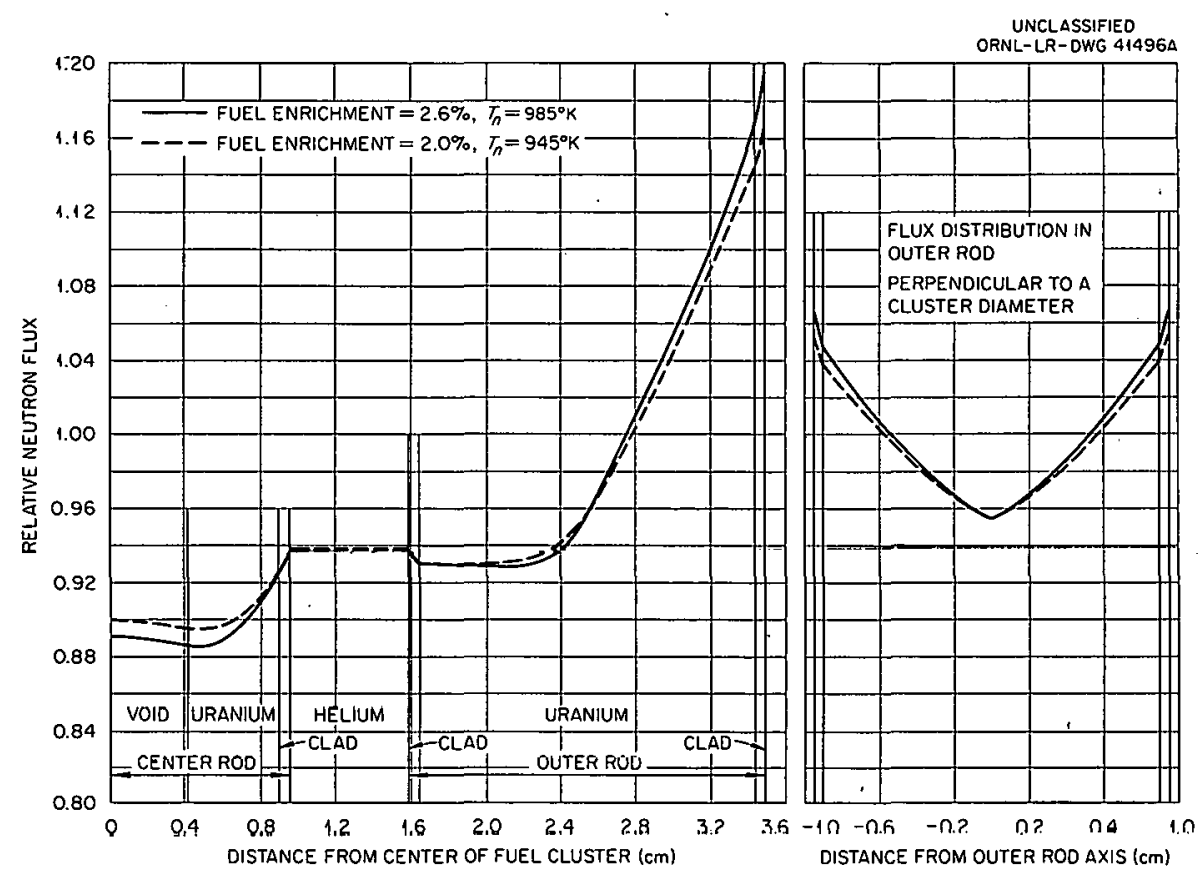

Fig. 5. Radial Flux Distribution in Fuel Cluster.

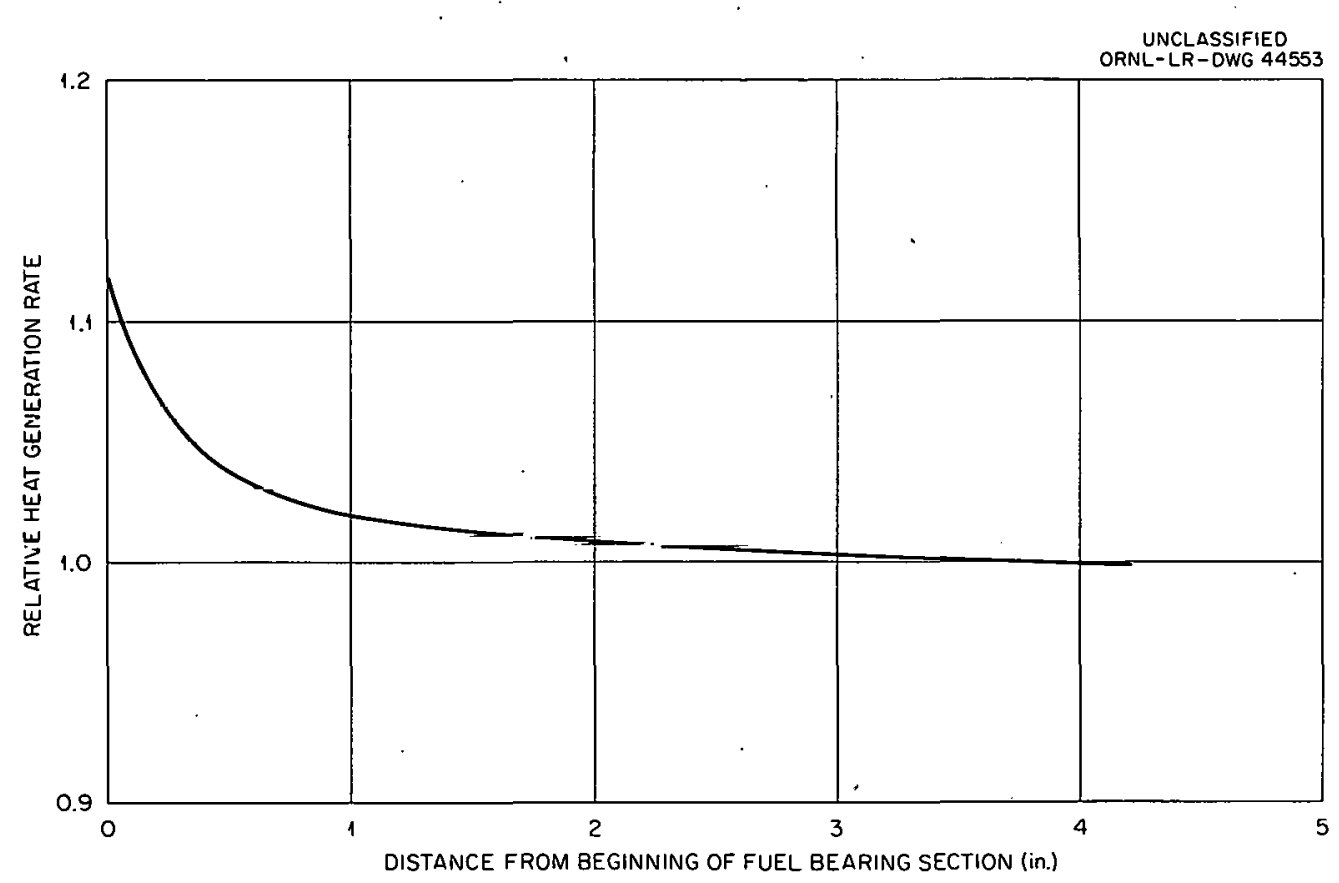

Fig. 6. Axial Variation of Heat Generation Rate at the End of an Element. 


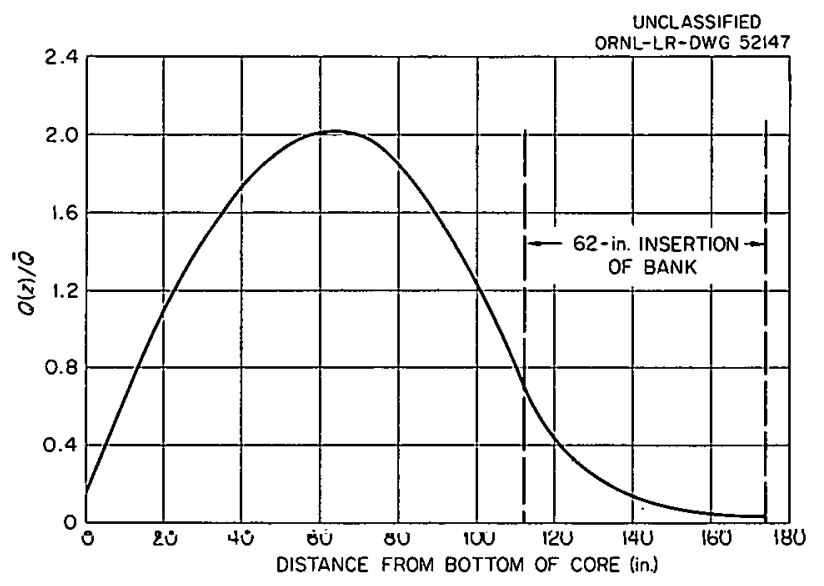

Fig. 7. Axial Variation of Heat Generation Rate Along Highest Power Channel for Bank Insertion of Control Rods to 62 in.

\section{Correlation of Heat Transfer and Mixing Data}

In analyzing the thermal and flow behavior of the EGCR design, each element is divided into three surface areas and the flow passage into four sections, as shown in Fig. 8. The average heat transfer coefficient is then determined from each of the three surfaces. The line dividing flow

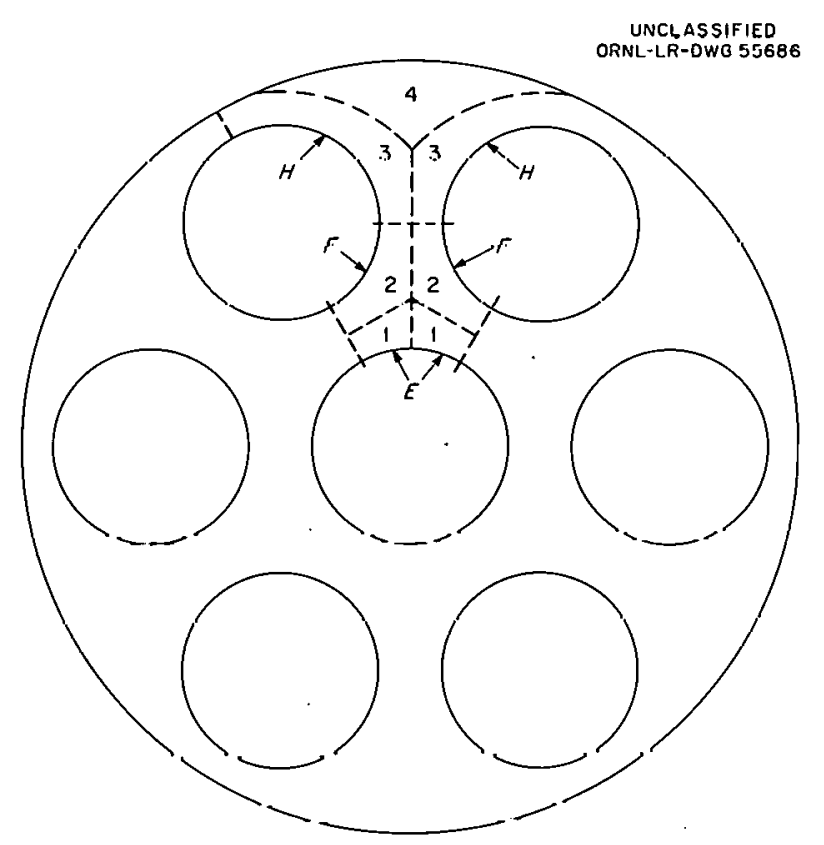

F18. 8. Flow and Surtace Sections Considered in Analysis of SevenElement Cluctcr. 
areas three and four is difficult to locate in the region near the tubes and is not too important in this region because of the eddy diffusivity mixing that equalizes the temperatures in the two sections.

Figure 4 shows the local velocity data for an $L / d_{e}$ of 3.9 and a zero-degree orientation reduced to lines of constant velocity. The velocity distribution was determined by graphical integration of the velocity profile. The ratio of the flow in regions three and four compared with the flow in regions one and two was then determined by the ratio of the flow areas. Values of this fllow ratio are given in Table 1. A cunparison of the values of Table $I$ indicates that the flow ratio has been shifted from the value that existed at the entrance of the first assembly, which would be the equal velocity value of 2.13, past the equilibrium value of 2.00 toward the calculated entrance value of 1.69. Some flow redistribution occurred between $\mathrm{L} / \mathrm{d}_{e}=0$ and $\mathrm{L} / \mathrm{d}_{e}=3.9$ toward establishing the equilibrium ratio value of 2.00 . In analyzing the heat and mass transfer data, it was assumed that the flow that was obtained at $\mathrm{L} / \mathrm{d}_{\mathrm{e}}=3.9$ for the aligned case was that which existed in the heat mass transfer experiments at $\mathrm{L} / \mathrm{d}_{\mathrm{e}}=0$ and shifted to the equilibrium flow ratio just upstream of the mid-cluster spacer. At the spacer it was assumed that the flow shifted to a rat1o value $01^{\prime \prime 2 . U y, ~ a s ~ d e t e r m i n e d ~ b y ~ t h e ~ s p a c e r ~ g e o m e-~}$ try, and then back to the equilibrium value just upstream of the bundle exit spider.

Table 1. Ratio of the Flow in the Outer Channels to the Flow in the Inner Channels

\begin{tabular}{ll}
\hline Calculated bundle entrance ratio, $\mathrm{I} / \mathrm{d}_{\mathrm{e}}=0$ & 1.69 \\
Ixperiment.n.1 rntio at, $\mathrm{T}_{1} / \mathrm{d}_{\mathrm{e}}=3.9$ & 1.88 \\
Equilibrium ratio & 2.00 \\
Ratio equal velocity in the outer and inner & 2.13 \\
channels &
\end{tabular}

In subdividing the cluster it was assumed that the heat and mass transfer of surface $\mathrm{E}$ is affected by the flow in region one, surface $\mathrm{F}$ by region two, and surface $H$ by region three. Flcw region four is 
essentially an area of bypass flow, and the performance of the assembly could be improved by scalloping the channel so that part of this area became the graphite sleeve. The data were then correlated by using a modified Colburn equation of the form

$$
N u_{S}=j_{H B} \operatorname{Re} \operatorname{Pr}_{S}^{0.4}
$$

where $\mathrm{Nu}_{\mathrm{s}}$ is the Nusselt number, Re is the Reynolds number, $\mathrm{Pr}$ is the Prandtl number, and $j$ is the Colburn $j$-factor. Subscript s refers all physical properties of the gas to the surface temperature; subscript $H$ refers to heat transfer; and subscript $B$ refers to the surface of the flow section in question. Rewriting Eq. (I) in the Dittus-Boelter form and referring the Reynolds number to the average cluster flow gives

$$
N_{s}=j_{H B}\left(\operatorname{Re}_{a} \frac{D_{B}}{D_{a}} \frac{G_{B}}{G_{a}}\right)^{0.2}\left(\operatorname{Re}_{a} \frac{D_{B}}{D_{a}} \frac{G}{G_{a}}\right)^{0.8} \frac{T_{a}}{T_{s}} \frac{\mu_{a}}{\mu_{s}} \operatorname{Pr}_{s}^{0.4},
$$

where $D$ is equivalent diameter, $G$ is mass velocity, $T$ is absolute temperature, $\mu$ is viscosity, and subscript a denotes average and also refers the properties of the gas to average or bulk conditions. Letting

$$
C_{H B}=j_{H B}\left(\operatorname{Re}_{a} \cdot \frac{D_{B}}{D_{a}} \frac{G_{B}}{G_{a}}\right)^{0.2}
$$

and substituting in Eq. (2)

$$
\operatorname{Mu}_{\mathrm{s}}=\mathrm{C}_{H B}\left(\operatorname{Re} \frac{\mathrm{D}_{\mathrm{B}}}{\mathrm{D}_{\mathrm{a}}} \frac{\mathrm{G}_{\mathrm{B}}}{\mathrm{G}_{\mathrm{a}}}\right)^{0.8} \frac{\mathrm{T}_{\mathrm{a}}}{\mathrm{T}_{\mathrm{s}}} \frac{\mu_{\mathrm{a}}}{\mu_{\mathrm{s}}} \operatorname{Pr}_{\mathrm{s}}^{0.4}
$$

The mass transfer $j_{M}$ (subscript $M$ refers to mass transfer) is then currected from the average cluster velocity to the Local velocity and used in the mass transfer-heat transfer analogy to determine the corresponding mass coefficient $\mathrm{C}_{\mathrm{M}^{*}}$ Thus

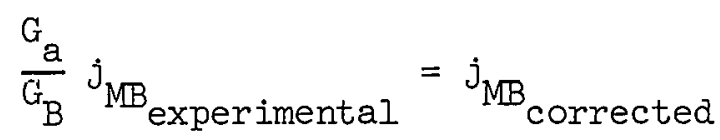


and

$$
C_{M B}=j_{M B} \text { corrected }\left(\operatorname{Re}_{a M} \frac{D_{B}}{D_{a}} \frac{G_{B}}{G_{a}}\right)^{0.2} \text {. }
$$

A comparison was made of the heat transfer coefficients obtained from Allis-Chalmers' heat transfer experiments performed on a sevenelement cluster with the final spacer design and the coefficients from heat transfer experiments performed on flow through round tubes at NACA ${ }^{13}$ and at Stanford University ${ }^{14}$ with the mass transfer coefficient obtained for a completely simulated EGCR fuel element. The values of $\mathrm{C}_{\mathrm{HB}}$ and $\mathrm{C}_{\mathrm{MB}}$ for the three surface areas and the average for the cluster are shown in Figs. 9 through 12. The values of $\mathrm{C}_{\mathrm{HB}}$ from the NACA and Stanford reports are also shown. In general, the agreement between the ciuster heat and mass transfer coefficients is within $7 \%$ and within 10\% (with the exception of the first half of the center element, which is within 20\%) of the NACA and Stanford data. All the experiments were made with air, except the Stanford tests. The Stanford data shown in the figures were obtained with

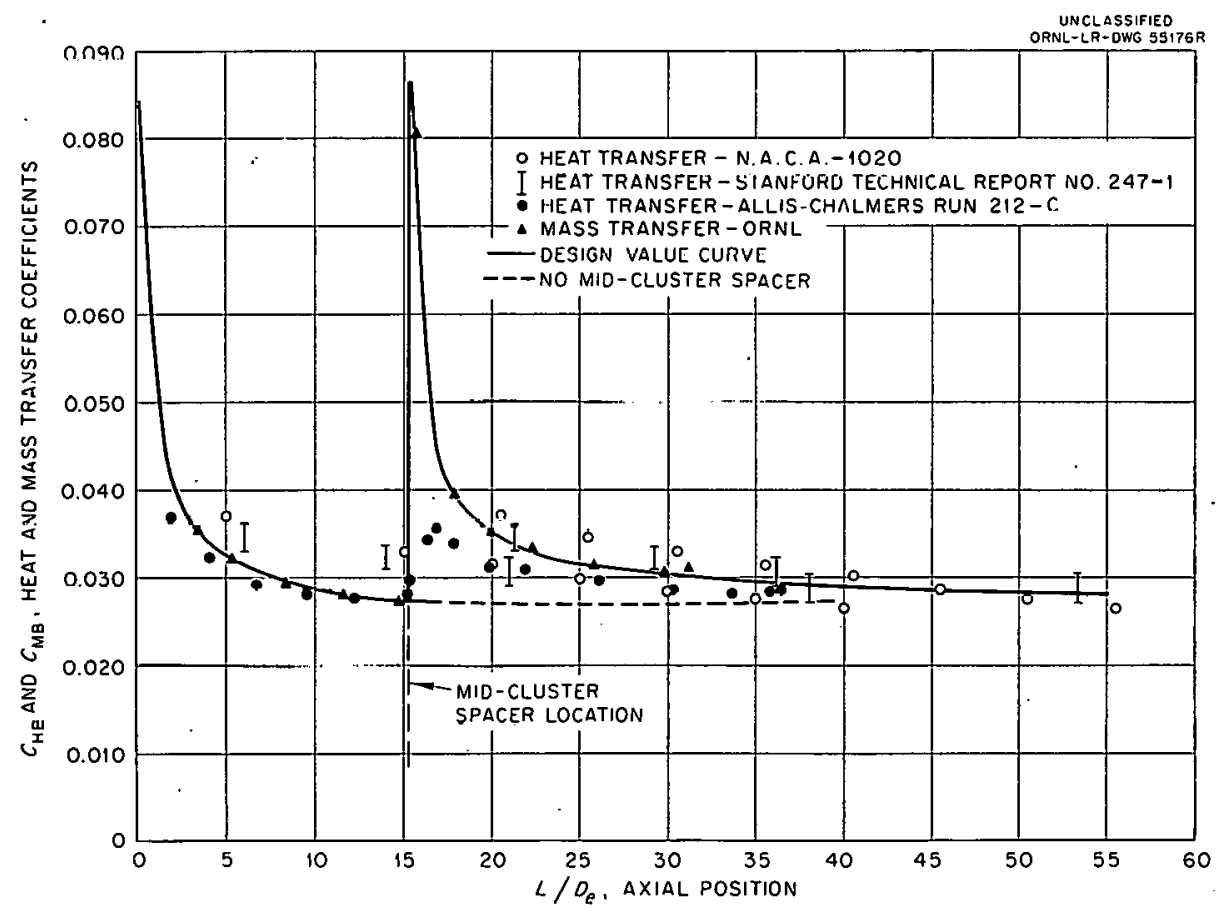

Fig. 9. Heat and Mass Transfer Coefficient for Section E. 


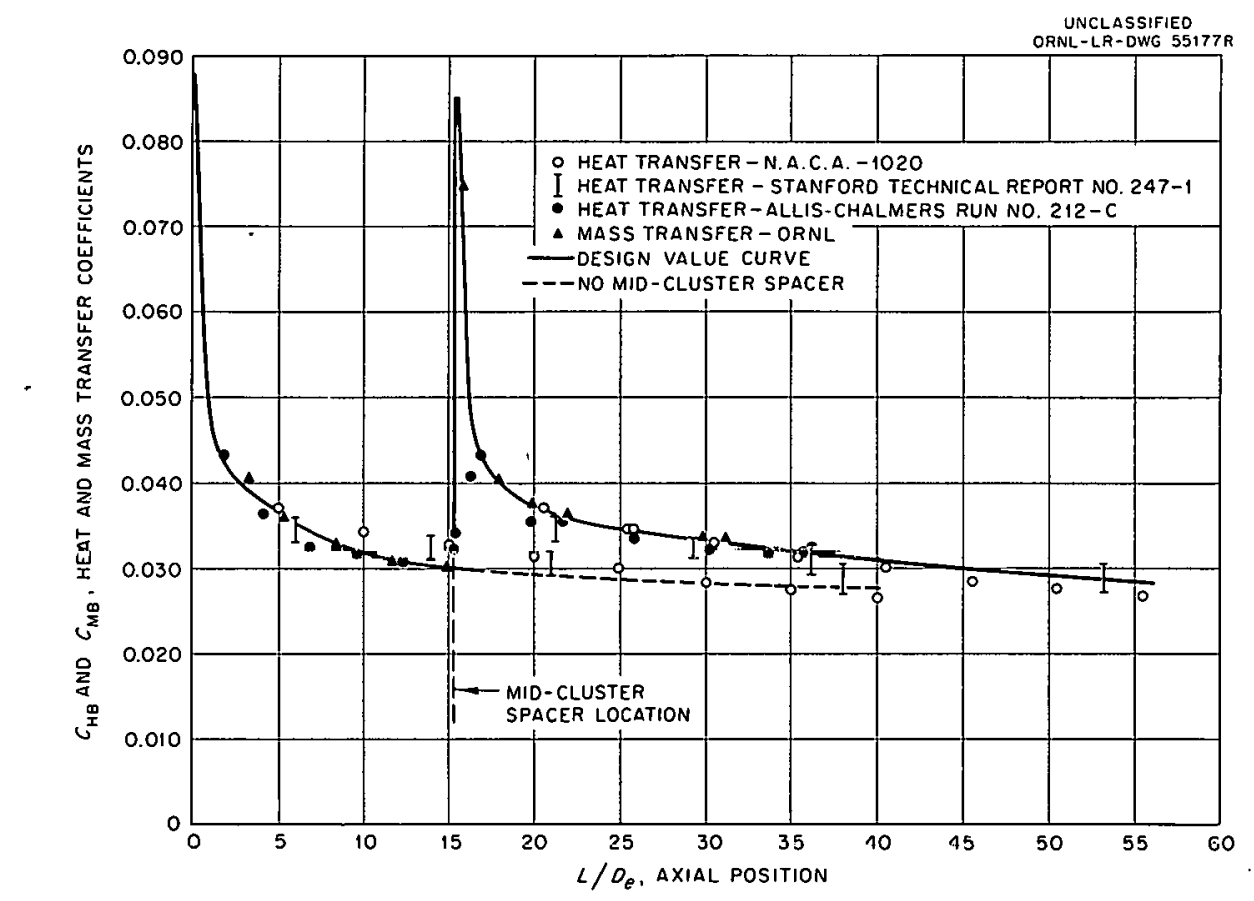

Fig. 10. Heat and Mass Transfer Coefficient for Section F.

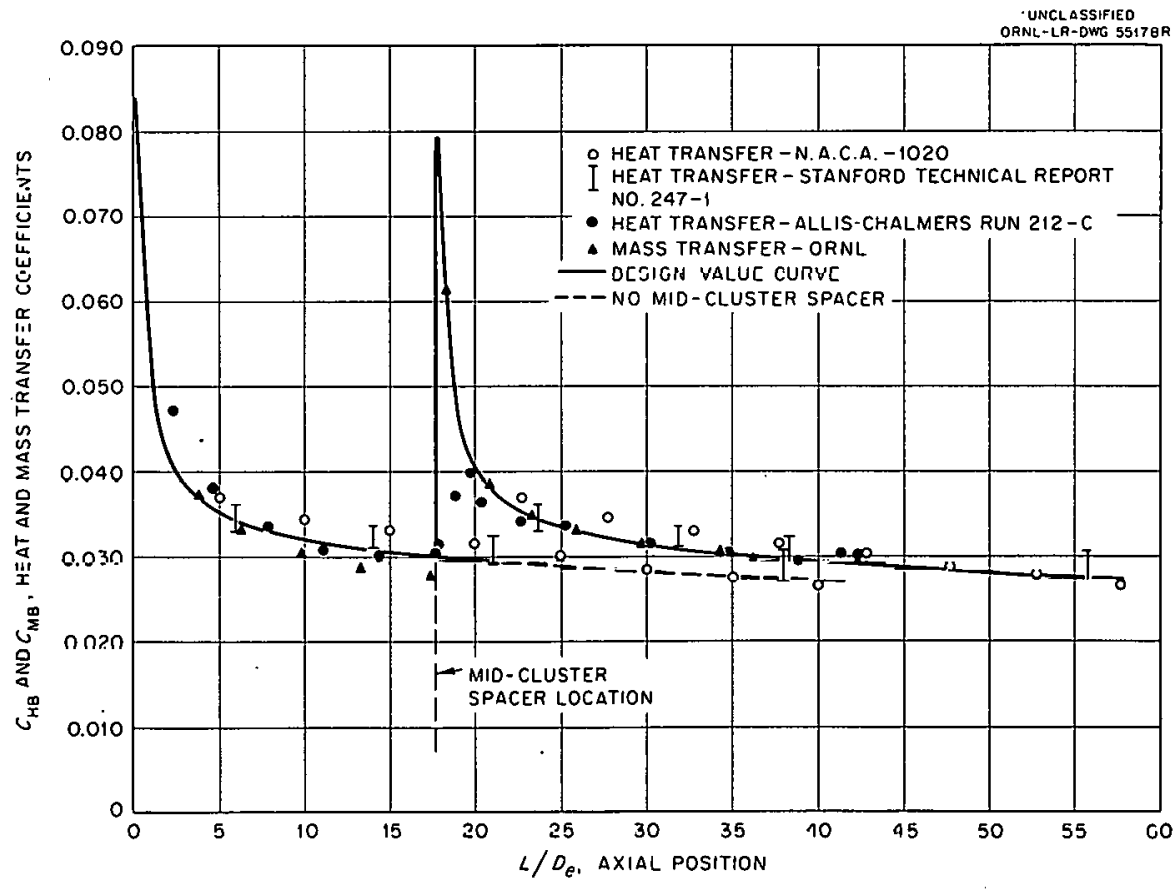

Fig. 11. Heat and Mass Transfer Coefficient for Section H. 


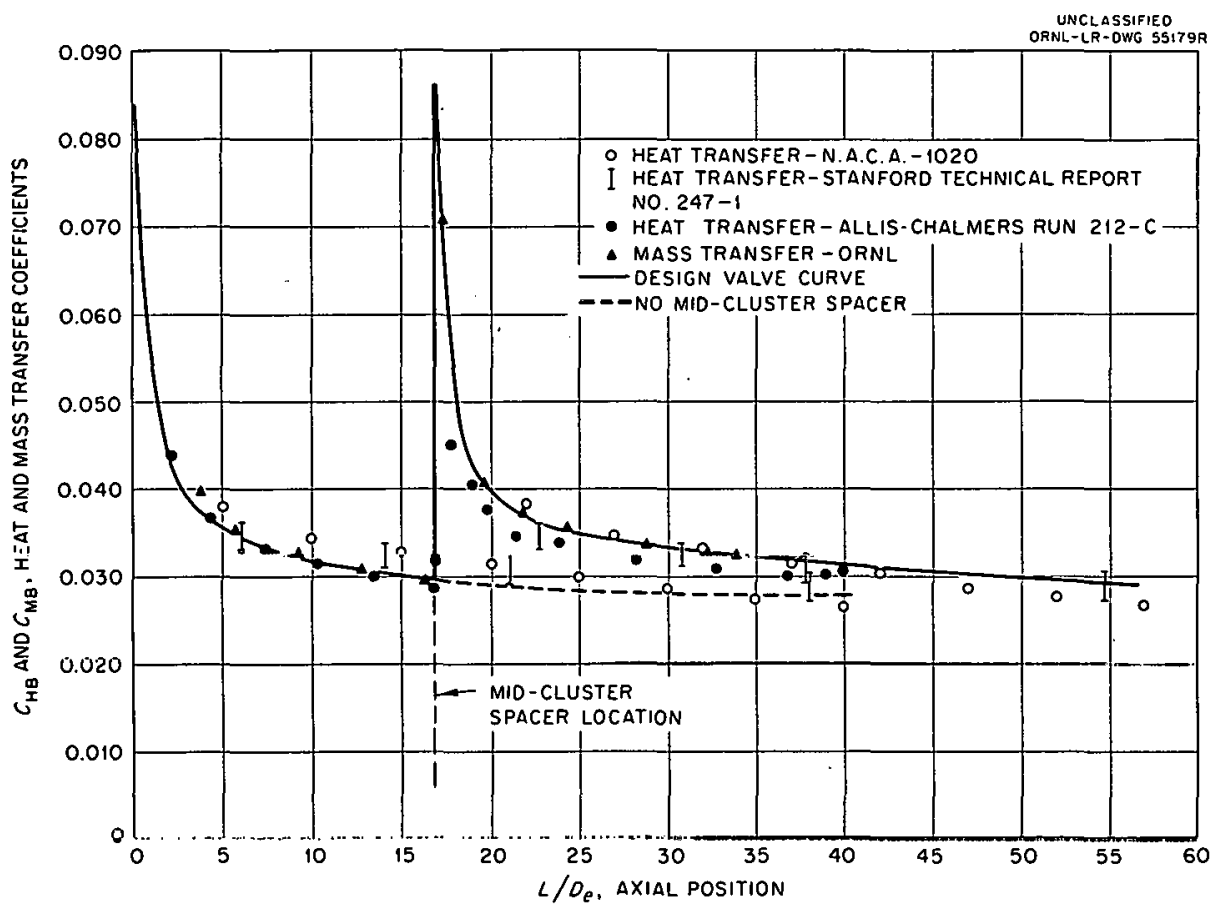

Fig. 12. Average Heat and Mass Transfer Coefficient for a SevenElement Cluster.

nitrogen. Data were also given in the Stanford report for hellum, and good agreement was found for the larger $\mathrm{L} / \mathrm{d}_{\mathrm{P}}$ values, but the effect of $\mathrm{L} / \mathrm{d}_{\mathrm{e}}$ on the coef'ticient was not as great as shown in Figs. 9 through 12. Application of these correlations to reactor design requires a know $1-$ edge of the properties of helium and the relative behavior of helium and air as coolants. Two curves for the thermal conductivity of helium are shown in Fig. 13. Prior to 1960 the lower curve represented what appeared to be the best consensus of opinion as to this property; ${ }^{15,16}$ however, much of this information represented a theoretical extrapolation of roomor low-temperature data to the higher temperatures. The upper curve is based on data from two reports 17,18 of experimental determinations, one at the upper temperature range and one at the lower. It is interesting to note that the upper curve agrees very well with a calculated line computed from kinetic theory and viscosity data reported by Nicklin. ${ }^{19}$ Although the higher values of thermal conductivity now appear to be correct, the lower values have been used throughout this thermal analysis. As the heat transfer coefficient is proportional to the 0.6 power of the thermal 


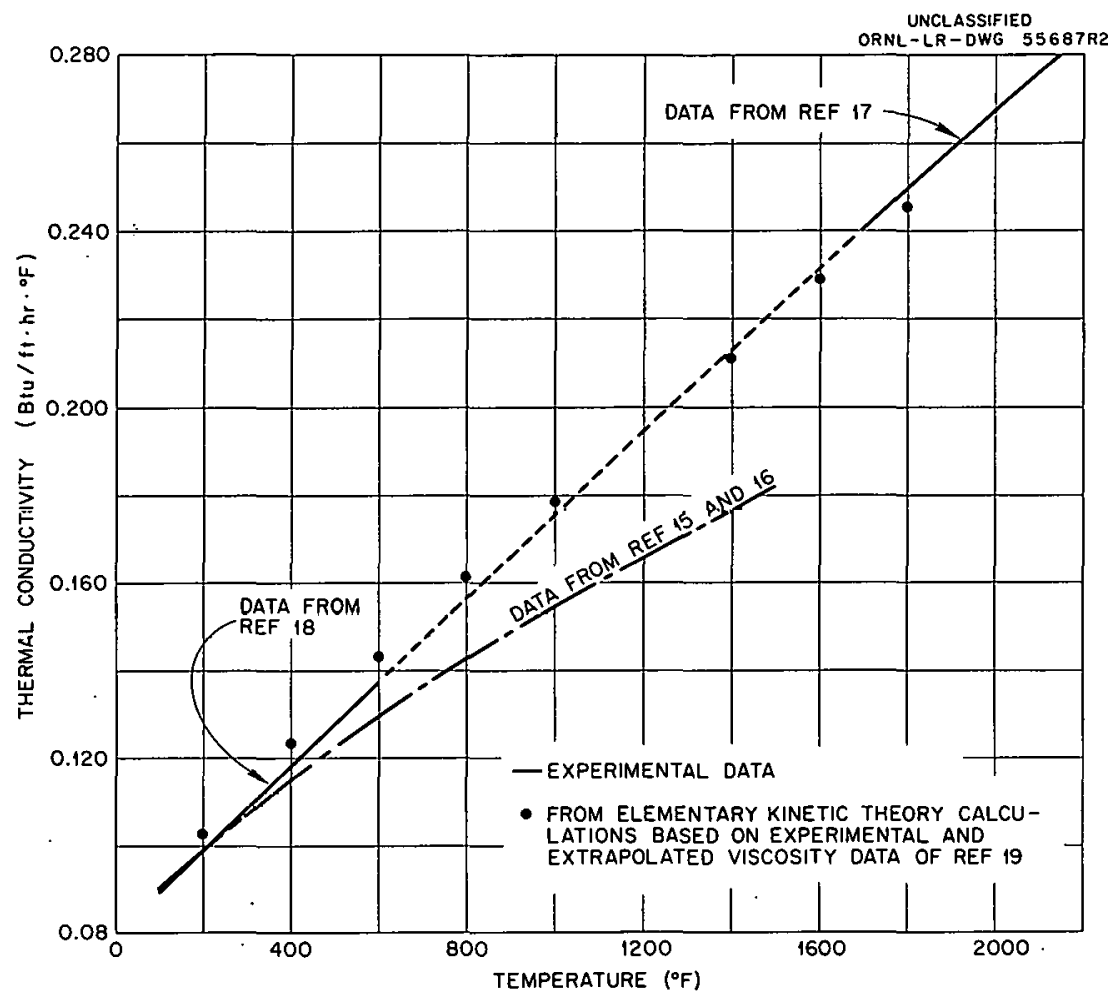

Fig. 13. Thermal Conductivity of Helium.

conductivity and the correlations are based on surface temperature properties, the use of the lower curve results in computed fuel element surface temperatures that are probably $60^{\circ} \mathrm{F}$ too high.

In addition to the Stanford report, ${ }^{1 / 4}$ which compared the heat transfer coefficients for helium, nitrogen, and carbon dioxide, a recent NASA report 20 compares results obtained for helium with those for air and indicates that the helium data are slightly higher than the data for air. The thermal conductivity of helium used in this report was taken from the lower curve of Fig. 13 and probably accounts for the difference between the ORIV data and the NASA data. The Stanford and INASA reports show that the air data apply very well to helium at the higher Reynolds number of interest, with the agreement well within the error introduced by the uncertainties in the physical properties of the gases used.

Two conclusions can be drawn from the data from the gas mixing studies. The first is that neither the mid-cluster spacers nor the top and bottom spiders in the aligned orientation induce any gross mixing in 
the channel. The second is that the mixing found agrees with that predicted from the turbulence or eddy diffusivity type of mixing in a turbulent stream. The second result permits a calculation of the degree of mixing between the various flow areas shown in Fig. 8. For the EGCR configuration the following equation was derived:

$$
K=k-\mu C_{p}+0.243 \rho V \text {, }
$$

where $K$ is total conductivity, $\mu$ is viscosity, $C_{p}$ is specific heat, $\rho$ is density, and $\mathrm{V}$ is velocity.

Thermal Analysis of Fuel Elements

The thermal analysis of the fuel elements consisted of (1) the determination of the nominal surface temperature of the elements along a channel and (2) the determination of the temperature asymmetries within the elements. The nominal surface temperature was determined by using the average gas temperature, average heat flux, and average heat transfer coefficient at the axial position being considered.

Because of the experimental nature of the EGCR the-thermal analysis of the fuel assemblies became a parametric study of the temperatures resulting from the many possibie modes of operation. During these investigations, several control rod operating schemes were found that resulted in fuel element temperatures 100 to $200^{\circ} \mathrm{F}$ less than that finally specified. In all these cases the control requirements were such that different control rods were inserted varying depths into the core. The change in the reactivity because of burnup required changing the location of the rods and shifting the radial flux gradient across the reactor. This then required that the variable orifices in many of the channels be reset to match the new heat generation rates. Although such changes could be made, the procedure would be quite time consuming; therefore these schemes were eliminated. The method finally specified minimizes the variations from reactivity changes and requires that most of the control rods act as a bank, with the depth of insertion of the bank determined by the excess reactivity. The heat generation rate along a channel for the case which results in the highest nominal fuel element surface temperatures is shown 
in Fig. 7. For this case the central control rod is fully inserted and the remaining control rods, operated as a bank, are inserted to a depth of 62 in. into the core.

Based on the axial flux profile of Fig. 7 and the correlation for the average heat transfer coefficient, the maximum nominal element surface temperature in the reactor was calculated as a function of the mixedmean exit gas temperature from all 232 channels and for two methods of orifice control. The results are shown in Fig. 14. The upper curve is for the case in. which the orifices are set to give a uniform exit gas temperature from all channels, and the lower curve is for the case in which the flow is controlled so that the maximum nominal surface temperature in each channel is the same. As may be seen from the curves, the

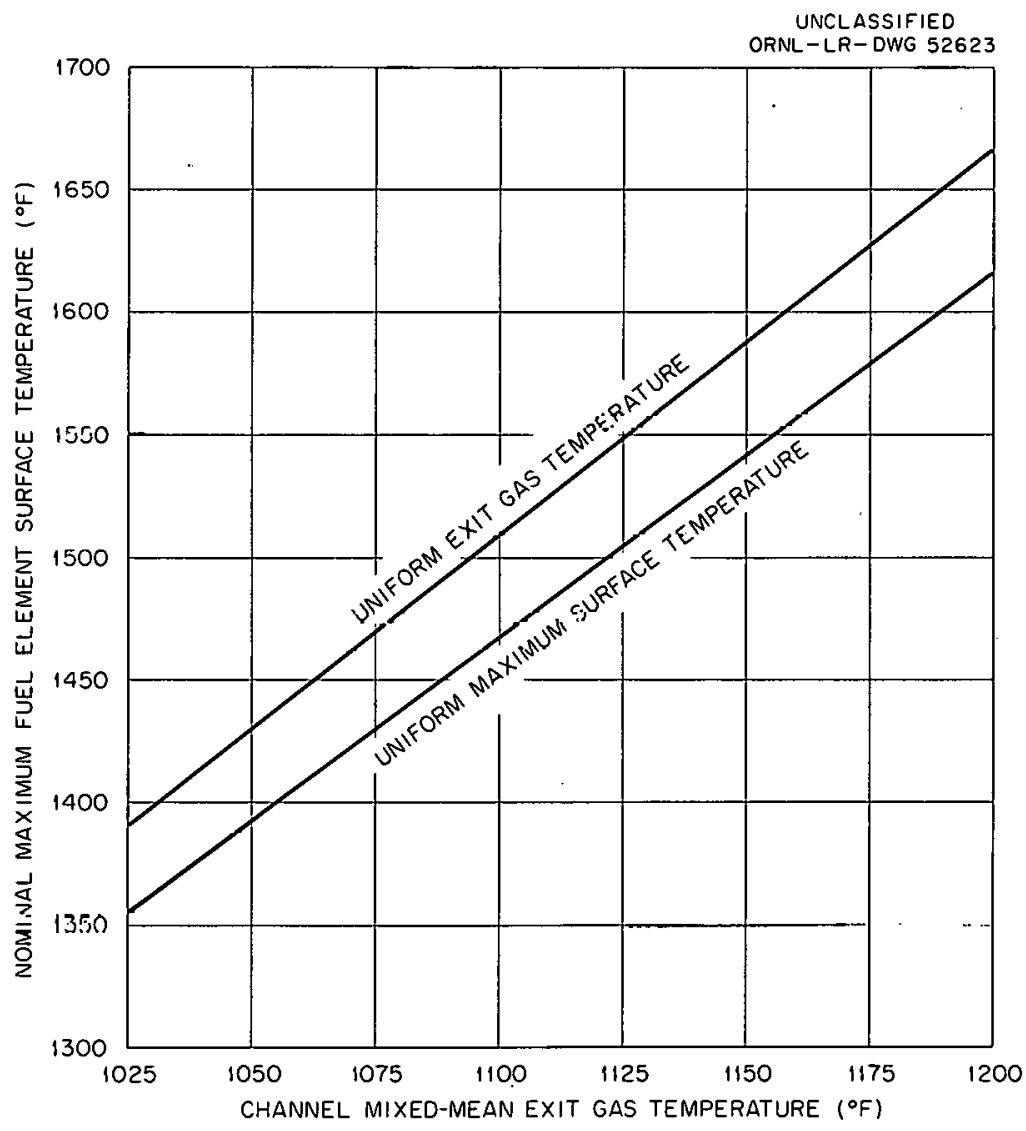

Fig. 14. Maximum Fuel Element Surface Temperature vs Mixed-Mean Exit Gas Temperature for Central Control Rod Fully Inserted and Bank Insertion of Remaining Rods to Depth of 62 in. 
reduction in surface temperature obtained by orificing for the maximum in all channels is about $40^{\circ} \mathrm{F}$. This method of operation is more difficult than that for the uniform exit gas temperature case, since it rcquires a knowledge of both the radial and axial flux profile, and it is certainly more susceptible to operational errors. The uniform exit gas temperature case was therefore used for design purposes.

Although the design gas outlet temperature is now specified as $1043^{\circ} \mathrm{F}$, the leakages in the core and the core and nozzle cooling requirements are such that the mixed-meurn exll yut lemperature from the chnnnolo must be $1075^{\circ} \mathrm{F}$. The gas and fuel element surface temperatures for the highest power channel and an exit gas temperature of $1075^{\circ} \mathrm{F}$ are shown in Fig. 15. The gas flow rates, exit gas temperatures, and maximum

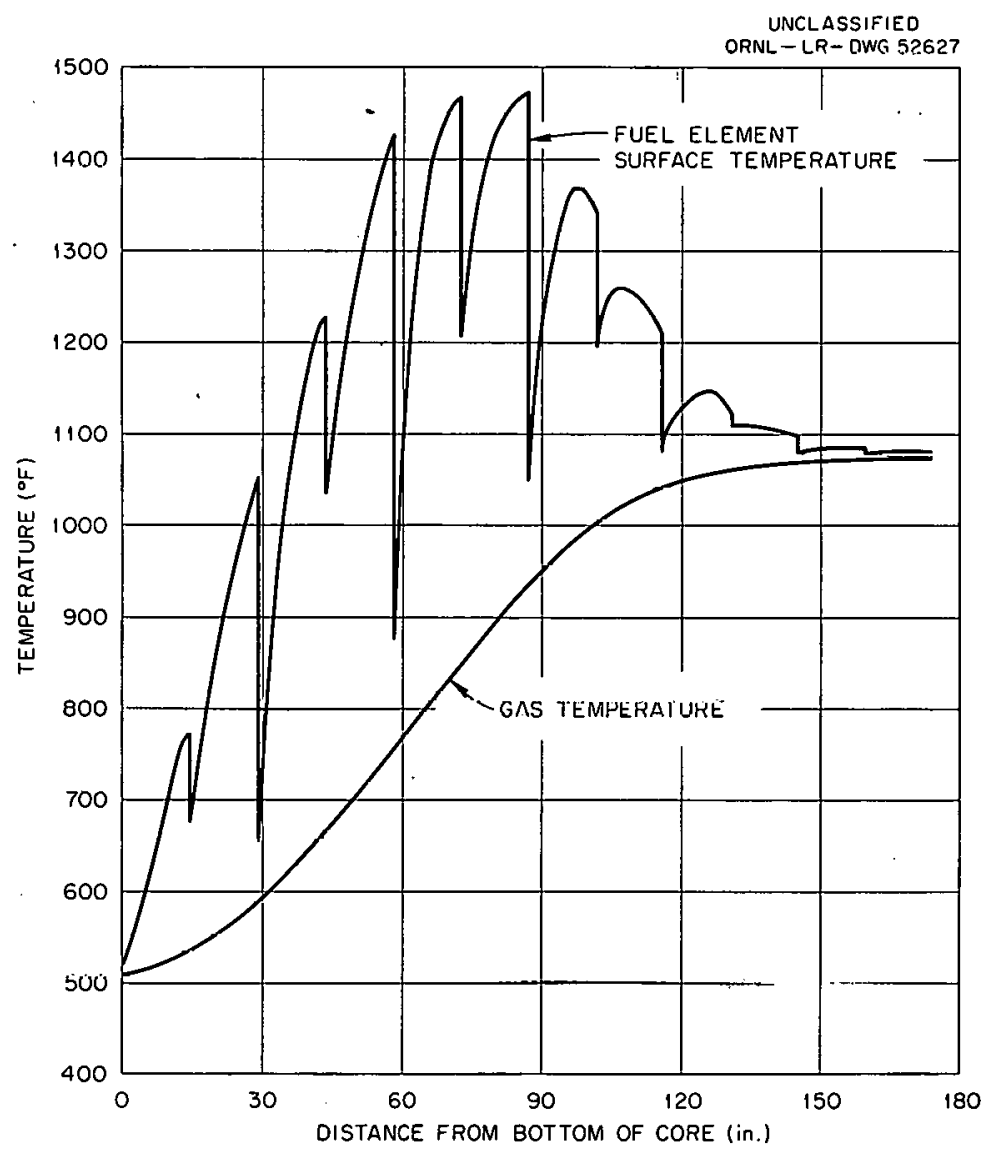

Fig. 15. Axial Temperature of Channel 4-20 for a Uniform Exit Gas Temperature and Bank Insertion of Control Rods to a Depth of 62 in. 
surface temperatures required to attain a mixed-mean exit gas temperature of $1075^{\circ} \mathrm{F}$ by the methods of orifice control described above are listed in Table 2. The data are shown for one octant of the core only but are applicable to the other seven because the fuel loading, experiments, and control rod pattern are symmetrical.

These nominal temperatures do not include temperature asymmetries, hot-channel factors, local flux peaks, or the effect of an empty fuel channel. When fuel is removed from one of the channels the heat generation rate in the adjacent t'our channels increases by $8 \%$ and 1 n the nexu four channels by $3 \%$. If the flow in these nearest channels is increased by $8 \%$ to match the increased heat rate, the surface temperature of the elements will increase by only $10^{\circ} \mathrm{F}$. If the orifices are not changed, the temperature will increase by $75^{\circ} \mathrm{F}$. Considering the time required to change the orifices of four channels both before and after each fuel change, the operator will much prefer to leave the settings constant and take the increased surface temperature for the period required to make the change. Since analyses have shown that this $75^{\circ} \mathrm{F}$ increase is not hazardous, the simpler mode of operation has been assumed.

Since the flux peaking at the end of an element occurs at a point where the heat transfer coefficient is a minimum and the surface temperature a maximum, a three-dimensional 21,22 relaxation calculation was made to determine the temperature throughout the end of an outer rod of the cluster. The axial and radial variations (Figs. 11 and 12) were considered, and both the gas temperature and heat transfer coefficient were assumed to be constant around the circumference of the rod. Although the operating conditions and the peak flux changed after these computations were made, the results of the investigation, presented in Fig. 16, are still valid. It may be seen that the end conduction through the $\mathrm{MgO}$ spacer and the end cap almost exactly offsets the increased generation rate. The effect of the peaking is to increase the temperature only 5 to $10^{\circ} \mathrm{F}$; the peak occurs about $3 / 4$ in. from the end of the $\mathrm{UO}_{2}$ and has completely vanished $2 \mathrm{in.} \mathrm{from} \mathrm{the} \mathrm{end.} \mathrm{It} \mathrm{is} \mathrm{also} \mathrm{interesting} \mathrm{to} \mathrm{note}$ that if the circumferential heat conduction through the $\mathrm{UO}_{2}$ and cladding had been ignored, the temperature difference would have been $105^{\circ} \mathrm{F}$ 
Table 2. Gas Flow Rates, Exit Gas Temperatures, and Maximum Surface Temperatures for all Channels for Bank Insertion of Control Rods to a Depth of 62 in. and for a Channel Mixed-Mean Exit Gas Temperature of $1075^{\circ} \mathrm{F}$

\begin{tabular}{|c|c|c|c|c|c|}
\hline \multicolumn{2}{|c|}{$\begin{array}{c}\text { Channel Group } \\
\text { Dimensions } \\
\text { (in.) }\end{array}$} & \multicolumn{2}{|c|}{$\begin{array}{l}\text { Uniform } \\
\text { Exit Gas } \\
\text { Temperature }\end{array}$} & \multicolumn{2}{|c|}{$\begin{array}{c}\text { Uniform Maximum } \\
\text { Surface } \\
\text { Temperature }\end{array}$} \\
\hline$x$ & $\mathrm{y}$ & $\begin{array}{l}\text { Flow } \\
\text { Rate } \\
(1 \mathrm{~b} / \mathrm{hr})\end{array}$ & $\begin{array}{l}\text { Maximum } \\
\text { Surface } \\
\text { Temperature } \\
\left({ }^{\circ} \mathrm{F}\right)\end{array}$ & $\begin{array}{l}\text { Flow } \\
\text { Rate } \\
(\mathrm{lb} / \mathrm{hr})\end{array}$ & $\begin{array}{c}\text { Exit } \\
\text { Gas } \\
\text { Tempcrature } \\
\left({ }^{\circ} \mathrm{F}\right)\end{array}$ \\
\hline 4 & $\begin{array}{r}4 \\
12 \\
20 \\
28 \\
36 \\
44 \\
52 \\
60 \\
68\end{array}$ & $\begin{array}{l}1589 \\
2021 \\
2283 \\
2278 \\
2140 \\
1925 \\
1669 \\
1395 \\
1223\end{array}$ & $\begin{array}{l}1366 \\
1416 \\
1470 \\
1468 \\
1466 \\
1454 \\
1423 \\
1404 \\
1383\end{array}$ & $\begin{array}{l}1448 \\
1996 \\
2379 \\
2375 \\
2218 \\
1964 \\
1663 \\
1354 \\
1171\end{array}$ & $\begin{array}{l}1130 \\
1082 \\
1052 \\
1052 \\
1055 \\
1064 \\
1077 \\
1092 \\
1100\end{array}$ \\
\hline 12 & $\begin{array}{l}20 \\
? .8 \\
36 \\
44 \\
52 \\
60 \\
68\end{array}$ & $\begin{array}{l}2237 \\
2.2 .36 \\
2082 \\
1.859 \\
1605 \\
1.359 \\
1240\end{array}$ & $\begin{array}{l}1470 \\
1467 \\
1461 \\
1447 \\
1420 \\
1401 \\
1381\end{array}$ & $\begin{array}{l}2331 \\
2322 \\
2146 \\
1882 \\
1593 \\
1317 \\
1184\end{array}$ & $\begin{array}{l}1052 \\
1054 \\
1058 \\
1068 \\
1079 \\
1093 \\
1102\end{array}$ \\
\hline 20 & $\begin{array}{l}20 \\
28 \\
36 \\
44 \\
52 \\
60\end{array}$ & $\begin{array}{l}2255 \\
2147 \\
1957 \\
1723 \\
1474 \\
1309\end{array}$ & $\begin{array}{l}1469 \\
1467 \\
1454 \\
1426 \\
1410 \\
1398\end{array}$ & $\begin{array}{l}2346 \\
2229 \\
2003 \\
1726 \\
1446 \\
1262\end{array}$ & $\begin{array}{l}1053 \\
1054 \\
1062 \\
1074 \\
1086 \\
1096\end{array}$ \\
\hline 28 & $\begin{array}{l}28 \\
36 \\
44 \\
52 \\
60\end{array}$ & $\begin{array}{l}1988 \\
1768 \\
1515 \\
1271 . \\
1134 .\end{array}$ & $\begin{array}{l}1456 \\
1431 \\
1414 \\
1385 \\
1373\end{array}$ & $\begin{array}{l}2038 \\
1777 \\
1491 \\
1219 \\
1072\end{array}$ & $\begin{array}{l}1061 \\
1072 \\
1084 \\
1099 \\
1108\end{array}$ \\
\hline 36 & $\begin{array}{l}36 \\
444 \\
52 \\
60\end{array}$ & $\begin{array}{c}1519 \\
1257 \\
1026 \\
921\end{array}$ & $\begin{array}{l}1416 \\
138 / 4 \\
1367 \\
1352\end{array}$ & $\begin{array}{r}1500 \\
1203 \\
961 \\
846\end{array}$ & $\begin{array}{l}1082 \\
1100 \\
1113 \\
1125\end{array}$ \\
\hline
\end{tabular}




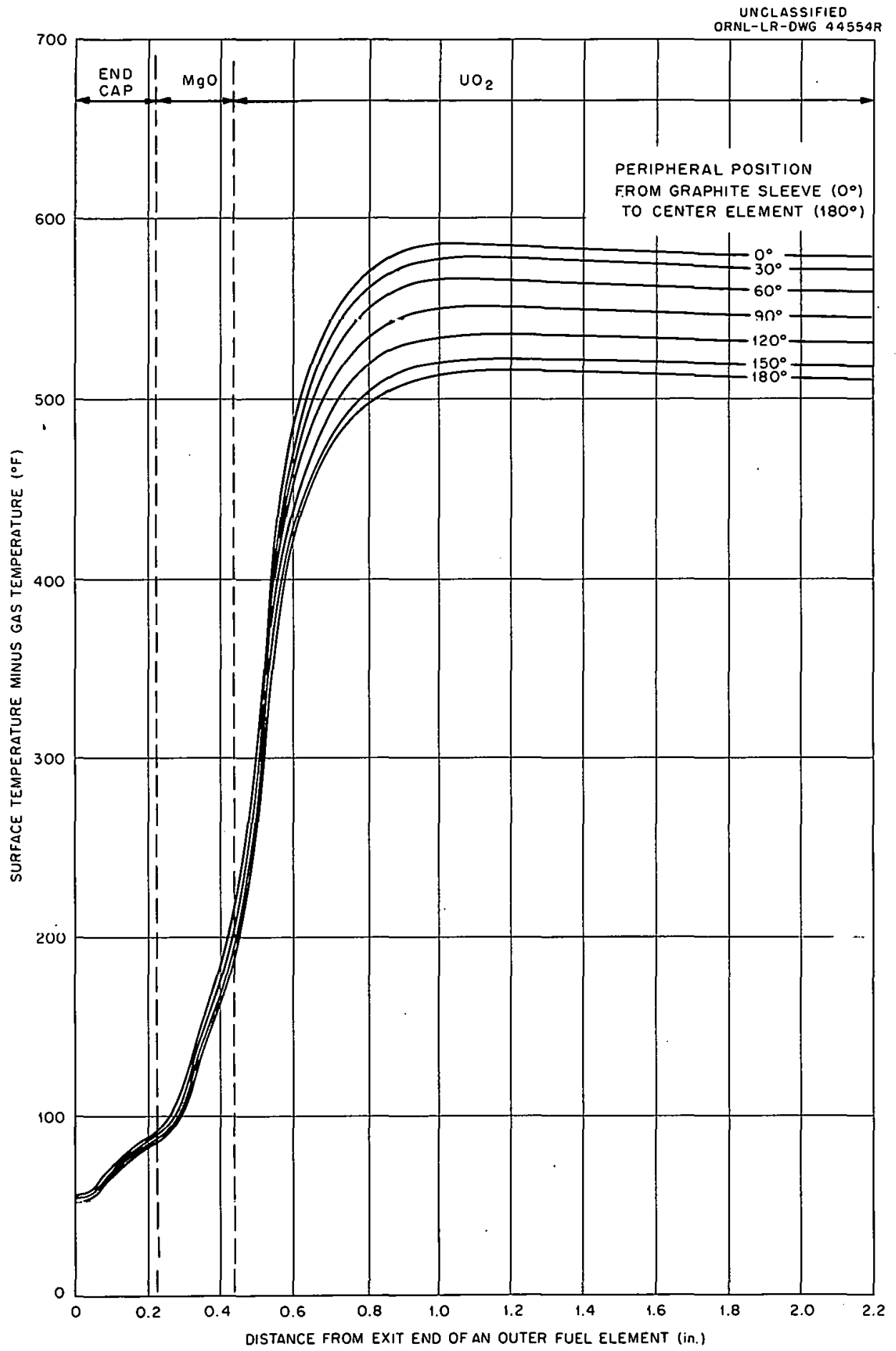

Fig. 16. Surface Temperature as a Function of Distance from Exit End of an Outer Fuel Rod for Various Peripheral Positions. 
instead of the actual $80^{\circ} \mathrm{F}$; the conduction through the element therefore decreased the temperature difference by $25^{\circ} \mathrm{F}$.

In calculating the local temperatures within the cluster the following effects were considered:

1. radial and axial heat generation gradient,

2. thermal radiation within the cluster,

3. variable heat transfer coefficient around the element and along the channel,

4. gas temperature dit't'erences between the várious t'low pásságès,

5. eddy diffusivity mixing between flow regions 3 and 4 (see Fig. 8),

6. circumferential heat conduction around the graphite sleeve.

The eddy diffusivity mixing from regions 1 and 2 to regions 3 and 4 was neglected, and the conduction through the elements was not considered, that is, the flow of heat in. the $\mathrm{UO}_{2}$ pellets was assumed to be radial only. Regions 1 and 2 were assumed to have the same gas temperature. The net thermal radiation ${ }^{23}$ from the three surfaces is shown in Fig. 17. The heat transfer coefficients were determined from Eq. (4) and the total conduction between regions 3 and 4. by Eq. (7). In applying the conduction between 3 and 4, a mean distance from heat flow between the two regions was determined from the geometry of the system, and the value of' $\mathrm{K} / \mathrm{x}$ was then treated as a heat transfer coefficient between the two regions. The results of calculations combining all these effects are shown in Fig. 18.

The temperature of surface $E$ is not shown because it was found to be very close to that of surface $F$. The difference in the temperatures of surfaces $F$ and $H$ gives the temperature difference across the outer elements which leads to bowing of these elements. It is interesting to note that the bowing torces on the elements are such that in the lower assemblies the bowing is outward and at the top of the channel the 'bowing is inward. This reversal of the temperature gradients emphasizes the problem of choosing the optimum location of the elements and shows that it is not possible to balance the temperature by adjusting the location of the elements.

The actual temperature gradients across the element will not be as large as those shown in Fig. 18. The mixing between the two inner and 


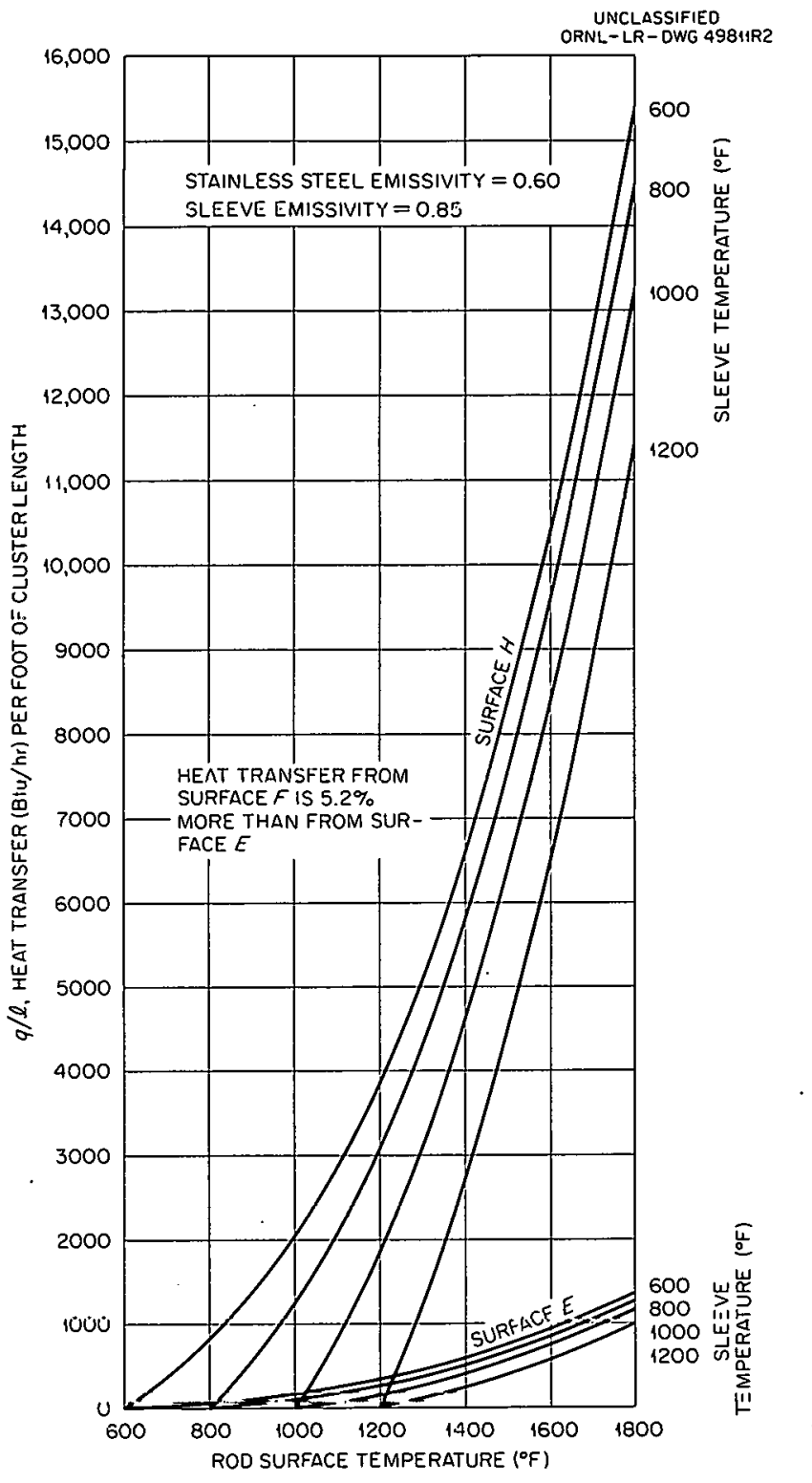

Fig. 17. Radiative Heat Transfer from Two Surfaces of Seven-Rod Cluster to Graphite Sleeve for Various Rod Surface and Sleeve Temperatures.

two outer regions will considerably reduce the difference in the gas temperatures between these regions and thus reduce the difference in temperatures of surfaces $F$ and $H$ at the top of a channel. At the end of the serond assembly, where the heat generation is highest, the conduction through the element will reduce the temperature across the element by 


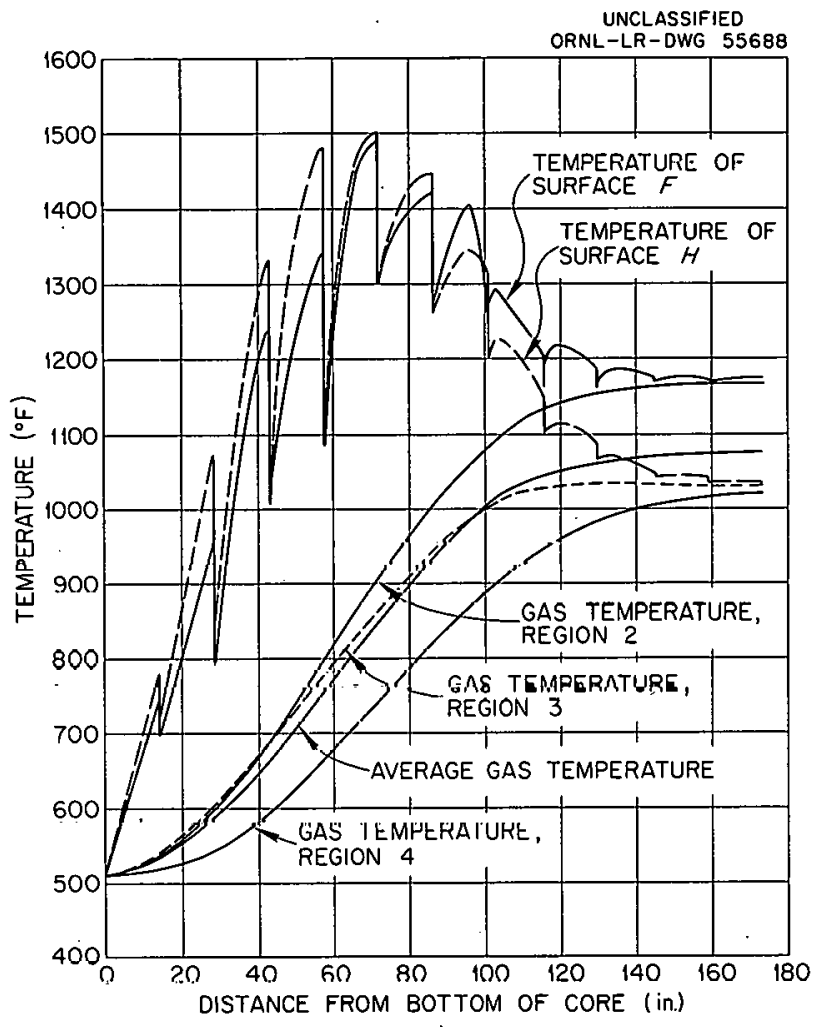

Fig. 18. Local Surface and Gas Temperatures for Uniform Exit Gas Temperature and Bank Insertion of Control Rods to 62 in.

about 30 or $40^{\circ} \mathrm{F}$, so the maximum difference will be 80 to $90^{\circ} \mathrm{F}$. At the top of a channel the difference will be well under $100^{\circ} \mathrm{F}$.

In calculating the maximum temperature that the elements will reach, an allowance of $75^{\circ} \mathrm{F}$ has been made for local effects. This is far above the $25^{\circ} \mathrm{F}\left(1500^{\circ} \mathrm{F}\right.$ of Fig. 18 compared with $1475^{\circ} \mathrm{F}$ for Fig. 15) calculated and provides for local variations within the regions considered, as well as for the fact that the data are still incomplete.

Studies 24,25 have been made to determine the ef't'ect of' a temperature gradient across an element for both restrained and unrestrained cases. The data of Corum and Shaw, 24 reproduced in Figs. 19 and 20, show the deflection of an element as a function of time for a constant temperature difference of $100^{\circ} \mathrm{F}$ along its entire length. Curves were not plotted for a mean temperature of $1100^{\circ} \mathrm{F}$, which would correspond to the temperature of the elements near the exit of a channel, because of the lack of data on creep rates at this temperature. The creep rate would be low. 


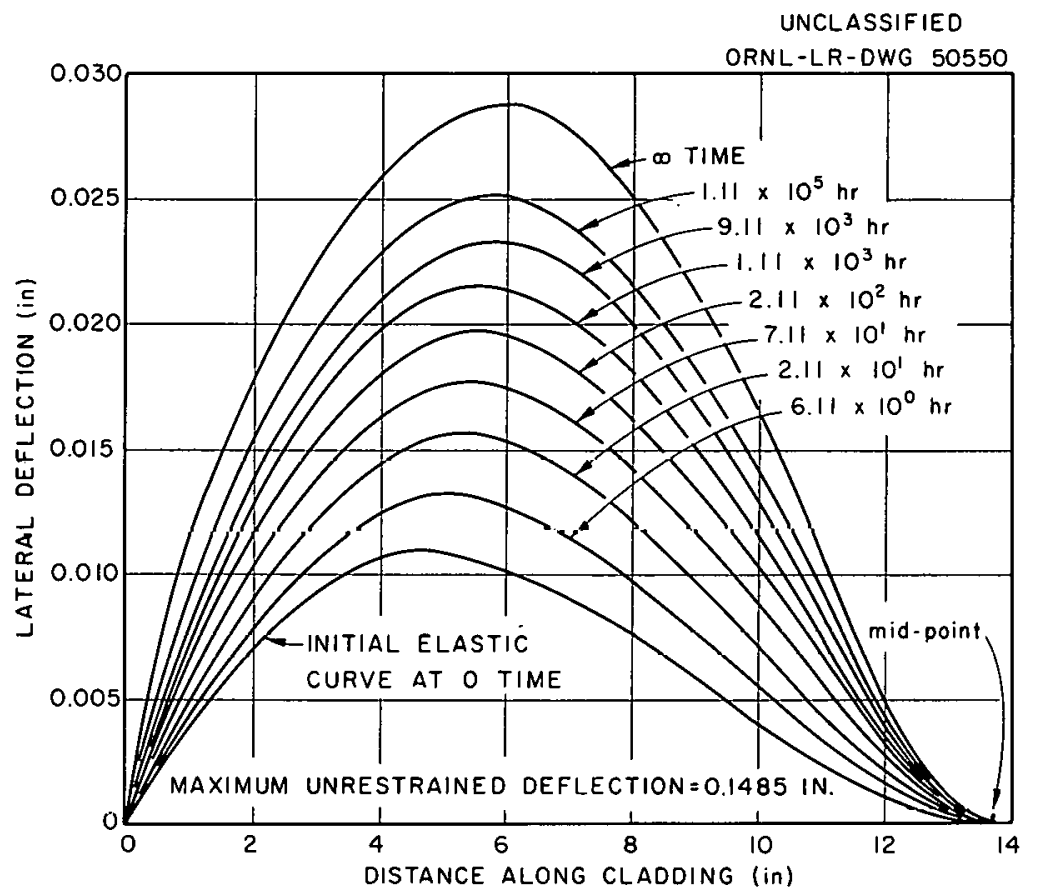

Fig. 19. Deflection of Fuel Rod vs Distance Along Cladding for a Mean Temperature of $1200^{\circ} \mathrm{F}$ and a Diametral Temperature Difference of $100^{\circ} \mathrm{F}$.

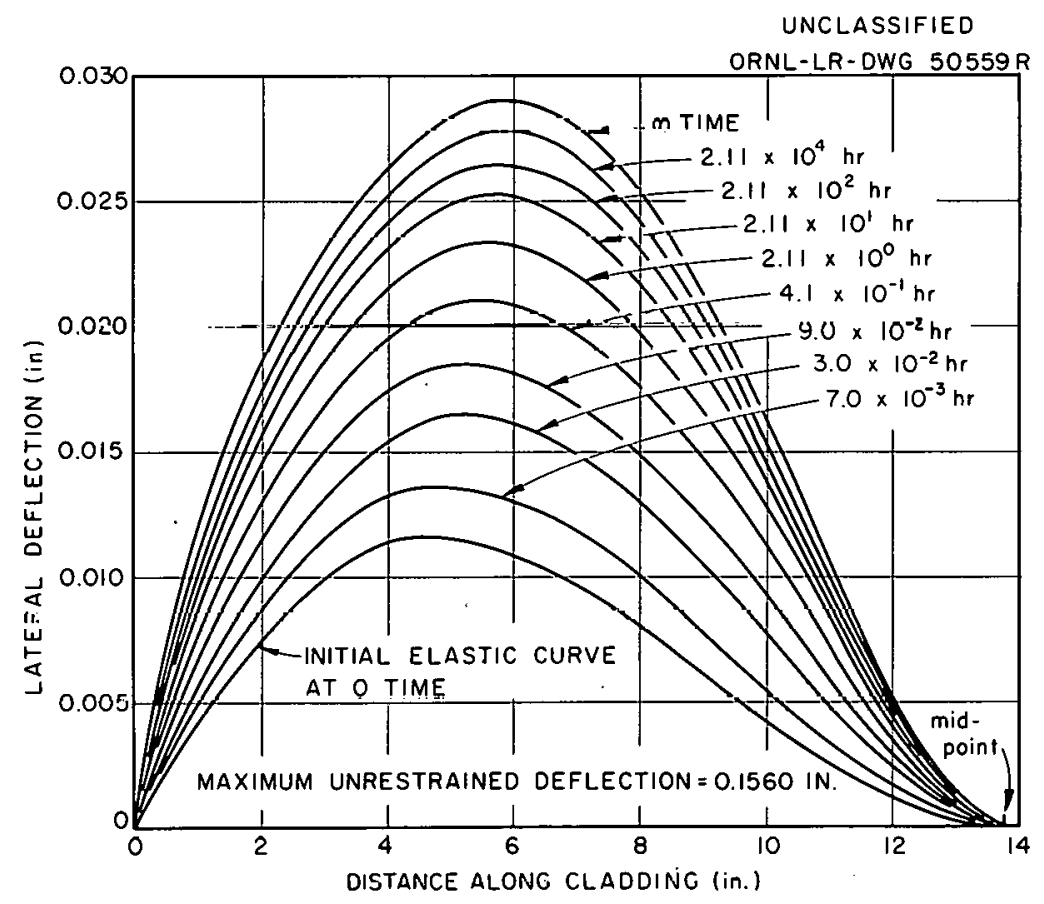

Fig. 20. Deflection of Fuel Rod vs Distance Alung Cladding for a Mean Temperature of $1500^{\circ} \mathrm{F}$ and a Diametral Temperature Difference of $100^{\circ} \mathrm{F}$. 
The fuel loading scheme for the reactor specifies that the upper three and lower three assemblies will be interchanged at their half life or after about 500 days. Assuming a $100^{\circ} \mathrm{F}$ constant temperature difference across the upper assemblies, it may be seen from Fig. 19 that the maximum deflection for a mean temperature of $1200^{\circ} \mathrm{F}$ would be about $0.023 \mathrm{in}$. At $1100^{\circ} \mathrm{F}$ this deflection would be much lower and less than $0.020 \mathrm{in}$. The permanent deflection will be the difference between the final deflection and the initial elastic curve and will be less than 0.010 in. For the second assembly from the bottom the temperature difference across the element varies from 50 to $70^{\circ} \mathrm{F}$ in the first half and from 40 to $90^{\circ} \mathrm{F}$ in the second half. The maximum deflection will be 0.020 to 0.025 in. and the permanent deflection about $0.010 \mathrm{in}$. At the time of interchanging the positions of the assemblies the permanent deflection of the elements will be in the direction to reduce the thermal gradients shown in fig. 18.

In considering the effect of the bowing on the temperature differences, it has been estimated ${ }^{26}$ that a $0.001-i n$. deflection of an element will cause an additional temperature difference of about $1^{\circ} \mathrm{F}$. Thus, the increase in temperature and additional bowing will be small.

\section{Fuel Element Hot-Channel Factors}

The term "hot-channel factor" as used here refer's not only to those factors which affect the entire channel but also to the local or "hot spot" effects. The surface temperature of a fuel element at a point in the reactor can be written as an explicit function of the physical characteristics of the fuel assembly and the parameters of heat generation and transfer. In the previous section this temperature was determined based on the expected values of these quantities. This section deals with the effect of deviations of these quantities on the previously calculated temperatures. The mathematical justification for the procedures used in this analysis has been described by Abernathy. 27

The hot-channel factors have been determined for both the normal operating case and for a channel with an additional 10\% heat output. In all cases the hot-channel factors have been applied to the highest power channel. In addition to using the highest power channel, the factors are 
applied to the case of 62-in. insertion of the control rods. Since this represents the most severe operating condition and gives the maximum flux peaking, the uncertainty in the flux applied in the calculations is quite small and represents only the uncertainty in the flux reported for the case considered. It is quite probable that the degree of accuracy with which the fluxes will be known for actual operating cases will be considerably less, but, since the conditions analyzed are considered maximum operating limits, the use of the smaller uncertainties is justifiable.

The largest single contribution to the hot-channe $\perp$ t'actors is the uncertainty in the heat transfer coefficient, which for these calculations is considered to be $\pm 10 \%$. The analys is of the experimental results shows the data to be well within $\pm 10 \%$ of the correlations used. In fact, the reported comparisons of the coefficients of helium to those of air and other gases and the conservative values used for the thermal conductivity of helium indicate that $\pm 10 \%$ is probably too large an uncertainty.

A total of 10 items is considered in the hot-channel analysis. Each of these items is treated as a random variable whose frequency function is assumed to be rectangular. The assumption that the frequency functions are rectangular is made both for simplicity and conservatism. When one specifies a dimension or design parameter as some value plus or minus a given uncertainty, it would be expected that the actual value would lie with the plus or minus bounds specified and most probably would peak near the specified value. Rather than attempt to anticipate the frequency function of each variable, it has been assumed that any value between the two extremes is equally likely, that is, a rectangular distribution.

The factors considered, the tolerance range on each, and their variance are listed in Table 3. Two cases are considered: normal operation and operation with an additional 10\% heat input. For normal operation the weight flow term is expressed in terms of five other variables which appear in this column. This is due to the "feedback" from the exit gas temperature reading and the orifice position. In the second case it is assumed that the channels receiving the additional 10\% power do not receive any additional flow. These conditions require a different analysis in that there is no longer any "feedback" from the exit gas temperature 
Table 3. Hot-Channel Factors

Outlet gas temperature: $1075^{\circ} \mathrm{F}$

Maximum surface temperature: $1466^{\circ} \mathrm{F}$

Film temperature drop at maximum surface temperature: $621^{\circ} \mathrm{F}$ Gas temperature rise to maximum surface temperature: $335^{\circ} \mathrm{F}$ Inlet temperature: $510^{\circ} \mathrm{F}$

\begin{tabular}{|c|c|c|c|c|c|}
\hline & & Normal or & eration & $\begin{array}{l}10 \% \text { Abo } \\
\text { Ope }\end{array}$ & $\begin{array}{l}\text { Normal } \\
\text { tion }\end{array}$ \\
\hline & - & Deviation & $\begin{array}{l}\operatorname{Variance} \\
\left.(0,1)^{2}\right)\end{array}$ & Deviation & $\begin{array}{l}\text { Variance } \\
\left({ }^{\circ} k^{12}\right)\end{array}$ \\
\hline 1. & Inlet temperature & $\pm 10^{\circ} \mathrm{F}$ & 7.458 & $\pm 10^{\circ} \mathrm{F}$ & 33.3 \\
\hline 2. & Fission cross section & $\pm 2 \%$ & 2.050 & $\pm 2 \%$ & 147.6 \\
\hline 3. & Radial flux & $\pm 1 \%$ & 0.513 & $\pm 1 \%$ & 36.9 \\
\hline 4. & $A x+a l$ flux & $\pm 2 \pi$ & 121.9 & $\pm 2 \pi$ & $14 \% \cdot 6$ \\
\hline 5. & Fuel volume per length & $\pm 11 / 2 \%$ & 28.92 & $\pm 11 / 2 \%$ & 35.03 \\
\hline 6. & Sleeve diameter & $\pm 1 / 6 \%$ & 4.320 & $\pm 1 / 6 \%$ & 5.23 \\
\hline 7. & Fuel rod diameter & $\pm 4 / 5 \%$ & 59.23 & $\pm 4 / 5 \%$ & 71.6 \\
\hline 8. & Heat transfer coefficient & $\pm 10 \%$ & 1285 & $\pm 10 \%$ & 1555 \\
\hline 9. & Thermocouple error & $\pm 25^{\circ} \mathrm{F}$ & 452.0 & & \\
\hline 10. & $\begin{array}{l}\text { Indicated thermocouple } \\
\text { reading }\end{array}$ & $\pm 25^{\circ} \mathrm{F}$ & 452.0 & & \\
\hline 11. & Coolant weight rlow & & & & 1314 \\
\hline & & $\sigma=$ & $.1^{\circ} \mathrm{F}$ & $\sigma=$ & $7.8^{\circ} \mathrm{F}$ \\
\hline
\end{tabular}

to the orifice position; thus, the precision with which the flow is known must be calculated for the normal operating case and then applied to the new conditions. The data for both cases are for the orifices set for a uniform exit gas temperature from all channels.

The variance of the sum of all the factors is the sum of the individual variances and the standard deviation of the sum of all factors is the square root of the variance. Thus, one has the standard deviation of some as yet unknown frequency function. As the number of factors considered increases, the frequency function of their sum must approach a normal frequency function. As shown by Abernathy, 27 the sum of five rectangular frequency functions very closely approaches normal, so the 
addition of another five factors can only further decrease the difference between the actual and a normal distribution. The probability results presented in Table 4 are therefore based on a normal distribution.

Table 4. Probability That Fuel Element Surface Temperature Will Exceed the Mean Surface Temperature by the Indicated Amount

\begin{tabular}{|c|c|c|}
\hline \multirow[b]{2}{*}{$\begin{array}{l}\text { Temperature } \\
\text { Difference } \\
\quad\left({ }^{\circ} \mathrm{F}\right)\end{array}$} & \multicolumn{2}{|c|}{ Probability } \\
\hline & $\begin{array}{l}\text { Normal Operation } \\
\overline{\mathrm{T}}=1466^{\circ} \mathrm{F} \\
\sigma=49.1^{\circ} \mathrm{F} \\
\text { Max. Dev. }=190^{\circ} \mathrm{F}\end{array}$ & $\begin{array}{l}\text { Operation at } 10 \% \\
\text { Above Normal } \\
\overline{\mathrm{T}}=1562^{\circ} \mathrm{F} \\
\sigma=57.8^{\circ} \mathrm{F} \\
\text { Max. Dev. }=284^{\circ} \mathrm{F}\end{array}$ \\
\hline 0 & 0.500 & 0.500 \\
\hline 10 & 0.420 & 0.431 \\
\hline 20 & 0.342 & 0.367 \\
\hline 30 & 0.270 & 0.301 \\
\hline 40 & 0.207 & 0.247 \\
\hline 50 & 0.152 & 0.192 \\
\hline 60 & 0.1115 & 0.150 \\
\hline 70 & 0.0770 & 0.113 \\
\hline 80 & 0.0520 & 0.0830 \\
\hline 90 & 0.0335 & $0.0600^{\circ}$ \\
\hline 100 & 0.0209 & 0.0415 \\
\hline 110 & 0.0125 & 0.0284 \\
\hline 120 & 0.0074 & 0.0189 \\
\hline 1.30 & 0.00405 & 0.0123 \\
\hline 140 & 0.00219 & 0.00775 \\
\hline 150 & 0.00111 & 0.00470 \\
\hline 160 & 0.00056 & 0.00283 \\
\hline 170 & 0.000275 & 0.00162 \\
\hline 180 & 0.000124 & 0.00093 \\
\hline 190 & 0.0000 & 0.00051 \\
\hline
\end{tabular}

Table 4 gives the probability of the surface temperature of any one element exceeding the expected temperature by the amount shown. The number of assemblies in any channel which can be subjected to these high uncertainties is two, the number of individual elements per channel is 14, and, for normal operation, the total number of elements in the reactor is 3248. The values in Tables 3 and 4 are based on a uniform exit gas temperature from all channels, so the lower power channels will have 
lower surface temperatures (see Table 3) and smaller hot-channel factors. Thus, the effective number of elements to which the probability figures of Table 4 are applicable will be somewhat smaller. The number of channels that may experience the temperature determined by the $10 \%$ above normal case will be limited to those adjacent to an empty fuel channel, or at most four channels. Thus, the number of elements to consider for this case at any one time is 56.

\section{F'ission-Gas-Kelease Studies}

In determining the amount of fission gas that will be released and pressure buildup that will result within a fuel element, the following data were used.

1. For normal operation, the diffusion parameter, $\mathrm{D}^{\prime}$, was taken to be $10^{-10} \mathrm{sec}^{-1}$ at $1400^{\circ} \mathrm{C}$, and an activation energy of $70 \mathrm{kcal} / \mathrm{g} \cdot \mathrm{mole}$ up to a temperature of $1600^{\circ} \mathrm{C}$ was assumed.

2. For long-time operation above $1600^{\circ} \mathrm{C}, 100 \%$ release of the fission gas was assumed.

3. For short-time accident conditions and a temperature of 1600 to $1800^{\circ} \mathrm{C}$, a linear release rate of $2 \%$ for the first $11 / 2 \mathrm{hr}$ and a release rate proportional to the square root of time thereafter were assumed. The additional release between $1 \mathrm{l} / 2$ and $9 \mathrm{hr}$ will be. $8 \%$.

4. For short times at temperatures between 1800 and $2000^{\circ} \mathrm{C}$, a linear rate of release of $1 \%$ per minute was assumed.

5. For short times at temperatures above $2000^{\circ} \mathrm{C}$, $100 \%$ release was assumed.

These design data are the results of an analysis ${ }^{28}$ of data from four types of studies: (1) postirradiation measurements of the rate of release of $\mathrm{Xe}^{133}$ or $\mathrm{Kr}^{85}$ from neutron-activated samples of $\mathrm{UO}_{2}$ over the temperature range of 1000 to $2000^{\circ} \mathrm{C}$, (2) postirradiation puncture tests of miniature capsules containing $\mathrm{UO}_{\text {? }}$ pellets irradiated in the LITR under EGCR conditions, (3) puncture tests of prototype EGCR fuel capsules after irradiation in the ORR and the ETR, and (4) measurements of instantaneous fission-gas release from $\mathrm{UO}_{2}$ during irradiation in the ORR. The actual 
values of $D^{\prime}$ at $1400^{\circ} \mathrm{C}$ found from the experiments ranged from $10^{-10}$ to $10^{-14}$; thus, the design value used is an upper limit for the release rate. The design data were applied to the EGCR operating conditions, and the $\mathrm{UO}_{2}$ temperatures and fission-gas pressure buildup were computed with the use of a code 29 developed for the IBM-704. In using the code an assumption must be made for the gas gap or contact resistance between the cladding and the $\mathrm{UO}_{2}$. For the results reported below the resistance was assumed to be equivalent to a $0.001-i n$. gas gap. The transfer of heat across the gap is by conduction and radiation, so, as the fission gases dilute the helium with which the capsule is originally filled, the conductance is reduced. The variation in conductance across this resistance for the element operating under the most adverse conditions is from $2100 \mathrm{Btu} / \mathrm{hr} \cdot \mathrm{ft}{ }^{2} \cdot{ }^{\circ} \mathrm{F}$ at initial conditions to about $580 \mathrm{Btu} / \mathrm{hr} \cdot \mathrm{ft}^{2} \cdot{ }^{\circ} \mathrm{F}$ at the end of an exposure of $9600 \mathrm{Mwd} / \mathrm{MT}$. This is the burnup received by any assembly experiencing the largest gas release in a channel which receives an average exposure of $9800 \mathrm{Mwd} / \mathrm{MT}$ for the entire channel of six assemblies.

In selecting the gap resistance for the elements, a number of factors was considered. The cold clearance between the cladding and $\mathrm{UO}_{2}$. pellets may vary from 0.002 to $0.006 \mathrm{in}$. on the diameter; that is, a mean gap of 0.001 to 0.003 in. Examination of the relative behavior of the cladding and pellet under reactor operating conditions shows that for the peak power region, which is of primary concern, the $\mathrm{UO}_{2}$ will outgrow the cladding and close the gap. Figure 21 shows the final hot clearance as a function of the cold clearance for 100\% helium as the fill gas and for a conductance of 0.276 times that of 100\% helium. This latter conductance is that for the gap at the end of life of an element. The conditions for this curve correspond to those existing at the highest temperature region of the reactor where the flssion-gas-release rate is a maximum. As the fission products are released from the $\mathrm{UO}_{2}$ the helium is diluted and the $\mathrm{UO}_{2}$ temperature increases and reduces the gap as shown by the lower clurve of Fig. 21 .

In addition to the expansion effechs, the cladding will collapse onto the pellets. Tests have been completed in which the temperature gradient in the $\mathrm{UO}_{2}$ has been simulated by a tantalum resistance heater inserted 


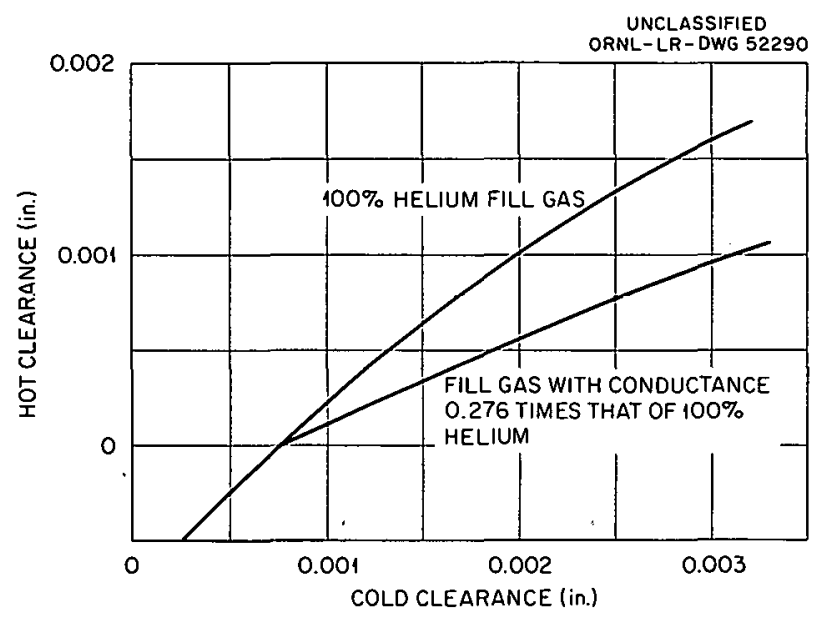

Fig. 21. Hot. Cilearanse Retween nladding and $\pi \Omega_{3}$ as a Function of Cold Clearance for Peak Power Region.

down the center of a stack of clad $\mathrm{UO}_{2}$ pellets. The cladding, when subjected to a mean temperature of $1400^{\circ} \mathrm{F}$ and an external pressure of 320 psia, collapsed onto the pellets in from 24 to $36 \mathrm{hr}$. No longitudinal wrinkle was formed even though the original diametral clearance was about $0.010 \mathrm{in.}$

No hot-channel factors have been applied to the analysis of the $\mathrm{UO}_{2}$ temperature or fission-gas release. The $\mathrm{UO}_{2}$ temperature is dependent on the four factors: heat generation rate, gap resistance, quantity of gases released, and thermal conductivity. The heat generation rate has been assumed to be the maximum (62-in. insertion of control rod bank) for the entire life of a fuel channel. The equivalent gap resistance used is the same as that assumed in the Preliminary Hazards Summary Report ${ }^{30}$ and is believed to be conservative. The flsston-gas release is calculated from the maximum value of $D^{\prime}$ found from the experimental program. The value of thermal conductivity is based on the data of Hedge and Fieldhouse 31 and has been found to be in fairly good agreement with the data for irradiated $\mathrm{UO}_{2}$ by both Westinghouse and Chalk River. Thus, the use of the upper expected value for three of the four factors affecting the $\mathrm{UO}_{2}$ temperature and fission-gas release lead to calculated values which are conservative, and no additional allowances are warranted. In addition, the fuel elements will be examined at different stages of their 
life in the reactor to determine the actual fission-gas-release rate and their life will be limited to prevent hazardous operation.

The internal temperature profile, fission-gas release, and internal pressure for each fuel assembly in the maximum power channel with the inversion fuel loading program have been computed using the fuel element life code. Table 5 gives the results of these calculations for the reactor operating with the central control rod fully inserted, the balance of the control rods inserted as a bank to a depth of $62 \mathrm{in.}$, and the fuel channels orificed for a uniform coolant outlet temperature of $1075^{\circ} \mathrm{F}$. As discussed above, a constant cladding- $\mathrm{UO}_{2}$ radial gap of 0.001 in., a noble fission-gas effective diffusion coefficient of $10^{-10} \mathrm{sec}^{-1}$ at $1400^{\circ} \mathrm{C}$, and a fission-gas diffusion activation energy of $70 \mathrm{kcal} / \mathrm{g} \cdot \mathrm{mole}$ up to $1600^{\circ} \mathrm{C}$ was assumed in this analysis. Since these fission-gas diffusion parameters apply only for $\mathrm{UO}_{2}$ temperatures of $1600^{\circ} \mathrm{C}\left(2912^{\circ} \mathrm{F}\right)$ or less,.. the axial temperature profile in each assembly was computed from the average cladding and $\mathrm{UO}_{2}$ temperatures of the fission-gas-release calculations and the detailed axial surface temperature and power distribution data: As shown in Fig. 22, approximately one-third of the length of the $\mathrm{UO}_{2}$ in channel position 4 has a small volume of $\mathrm{UO}_{2}$ at the inner surface of the pellets operating at a temperature in excess of $2912^{\circ} \mathrm{F}$. At the end of Iife, when the quantity of $\mathrm{UO}_{2}$ at this temperature is a maximum, it amounts to only $2 \%$ of the total oxide volume in the capsule. The fuel temperature exceeds $2912^{\circ} \mathrm{F}$ only during the last 120 days of irradiation (total exposure time is 1040 days); therefore the assumption of 100\% release of the fission gases generated in this volume increases the total internal pressure only from 178 to $192 \mathrm{psia}$ and the average gas release from 9.1 to 10.5\%. None of the fuel assemblies have final internal pressure in excess of the coolant pressure of $300 \mathrm{psia}$, and only the assembly in position 4 significantly exceeds an internal pressure of about 100 psia

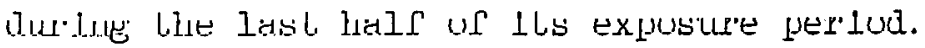

\section{Toilure Oritcria}

The ultimate objective of these analyses is to evaluate the overall performance of the fuel elements, which, in the reactor, will be measured 
Table 5. Results of Fuel Element Lif' Calculations

$$
\begin{aligned}
D^{\prime}{ }_{1400^{\circ} \mathrm{C}} & =10^{-10} \mathrm{sec}^{-1} \\
\mathrm{E}_{\mathrm{a}} & =70 \mathrm{kcal} / \mathrm{g} \cdot \mathrm{mol} \mathrm{a}
\end{aligned}
$$

\begin{tabular}{|c|c|c|c|c|c|c|}
\hline & \multicolumn{6}{|c|}{ Finel Assemb-y } \\
\hline & A & B & $\mathrm{C}$ & $\mathrm{D}$ & $\mathrm{E}$ & $F$ \\
\hline $\begin{array}{l}\text { Initial assembly pasition within fuel } \\
\text { channel }\end{array}$ & $I(t \subset p)$ & 2 & 3 & 4 & 5 & 6 (bottom) \\
\hline Heat generation rate, Btu/hr.ft & 800 & 4,500 & 19,000 & 32,700 & 30,800 & 14,900 \\
\hline Average surface temperature, ${ }^{\circ} \mathrm{F}$ & 1080 & 1,120 & 1,270 & 1,350 & 1,150 & 765 \\
\hline Peak surface temperature, ${ }^{\mathrm{a}}{ }^{\circ} \mathrm{F}$ & 1185 & 1,245 & 1,475 & 1,575 & 1,535 & 1,160 \\
\hline $\begin{array}{l}\text { Internal pressure at exposure-period } \\
\text { midpoint, psia }\end{array}$ & 43 & 49 & 77 & 172 & 99 & 51 \\
\hline $\begin{array}{l}\text { Proportion of fiss ion gas released at } \\
\text { exposure-period m-dpoint, } \%\end{array}$ & 3.0 & 3.0 & 3.0 & 8.8 & 3.5 & 3.0 \\
\hline $\begin{array}{l}\text { Fuel exposure at exposure-period mid- } \\
\text { point, Mwd/MT of uranium }\end{array}$ & 200 & 1,300 & 5,400 & 9,400 & 8,800 & 4,300 \\
\hline $\begin{array}{l}\text { Channel position of fuel assembly during } \\
\text { second half cf exposidre period }\end{array}$ & 4 & 5 & 6 & 1 & 2 & 3 \\
\hline Internal pressure at disciarge, psia & 192 & 107 & 61 & 84 & 66 & 87 \\
\hline $\begin{array}{l}\text { Proportion of fission gas released at } \\
\text { discharge, } \%\end{array}$ & 10.5 & 3.6 & 3.0 & 8.7 & 3.4 & 3.0 \\
\hline $\begin{array}{l}\text { Fuel expcsure at disciarge, Mwd/MI } \\
\text { of uranium }\end{array}$ & 9600 & 10,100 & 9,700 & 9,601 & 10,100 & 9,700 \\
\hline
\end{tabular}

Value given is $100^{\circ} \mathrm{F}$ above calculated maximum surface temperature to allow for kot s’ots. 


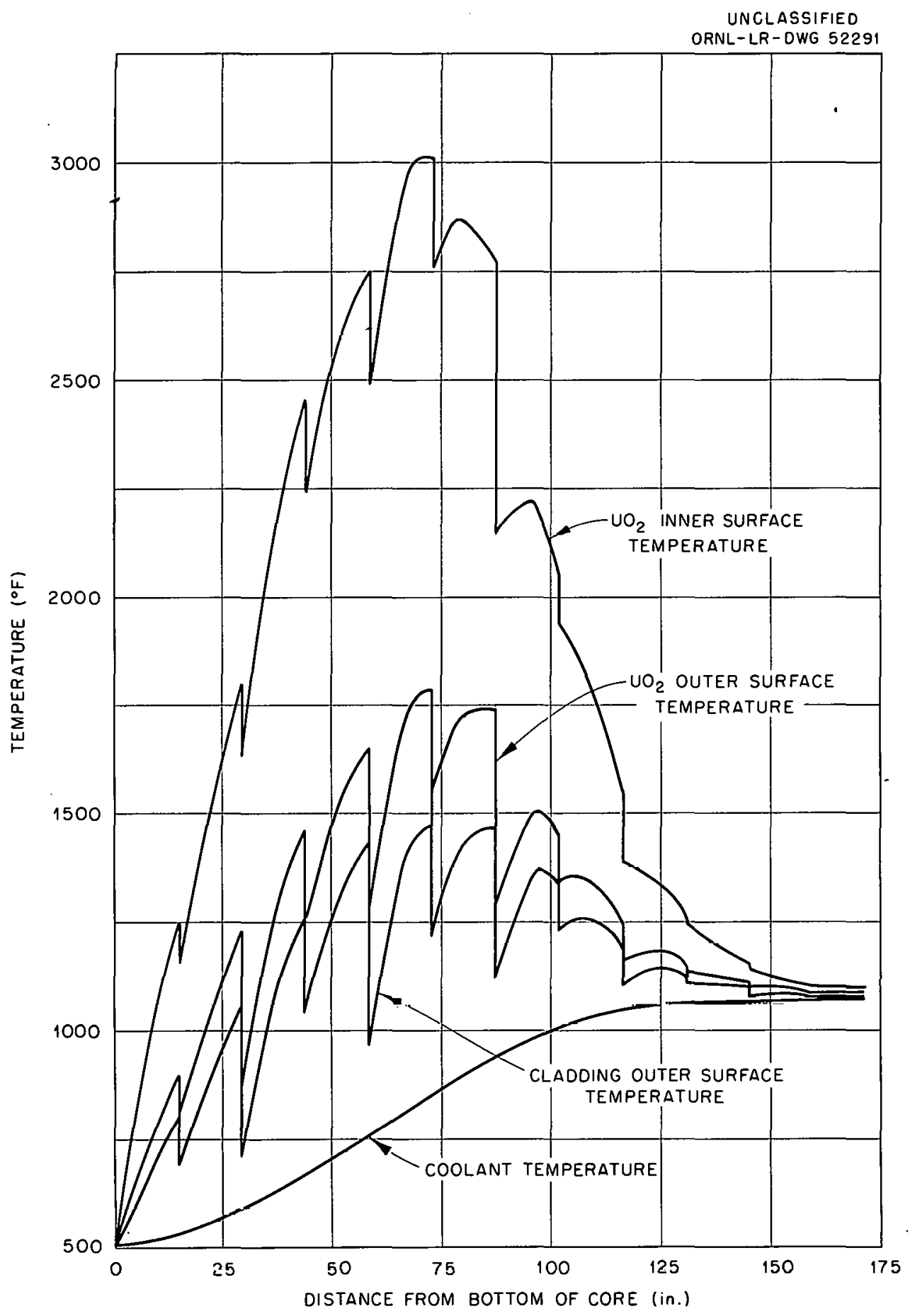

Fig. 22. Fuel and Coolant Axial Temperature Distribution for Channe.1. 4-20. 
by the number of failures. If it is assumed that the fuel assemblies are properly fabricated and inspected, the two factors which will lead to failure are excessive temperatures and excessive fission-gas release. Either of these factors or a combination of the two must be considered in estimating a failure rate for the EGCR fuel elements. The maximum allowable temperature has been set at $1800^{\circ} \mathrm{F}$, and any element operating above this temperature is assumed to fail. Both physical property and compatibility data on type 304 stainless steel are now available up to $1800^{\circ} \mathrm{F}$, and satisfactory operation at this temperature appears to be possible. The selection of $1800^{\circ} \mathrm{F}$ as the point of failure is based primarily on the lack of data above this temperature and not on any specific properties or reactions.

The second method of failure postulated for the fuel elements is rupture due to internal t'ission-gas pressure buildup. For this case it is assumed that the operating time of the element will be limited to the time when the internal pressure on the capsule is equal to the external pressure. Again, this limit is conservative because the cladding has considerable strength and any failure must result f'rom excessive creep strain and be time-dependent. It should be emphasized that this analysis is for normal long-time operation only. For short-time temperature excursions or the maximum credible accident in which the coolant system pressure is lost, the determination of failures should be based on the tube-burst data. 32

As can be seen from Table 5, the calculated internal pressure within the fuel element does not exceed the external pressure during the design lifetime, and failure from this cause should not occur. In examining a failure rate caused by excessive temperature, two cases must be considered; that is, normal operation with all channels containing fuel and the case in which one channel is empty and the four adjacent channels have an additional $8 \%$ heat generation rate caused by the flux peaking in the empty channel.

For the first case the maximum nominal surface temperature is $1470^{\circ} \mathrm{F}$. To this must be added the $75^{\circ} \mathrm{F}$ allowance for local temperature asymmetries for a maximum local surface temperature of $1545^{\circ} \mathrm{F}$. The difference between 
this value and $1800^{\circ} \mathrm{F}$ is $255^{\circ} \mathrm{F}$. Thus, the probability of an element failing by exceeding $1800^{\circ} \mathrm{F}$ is the probability of the hot-channel factor exceeding $255^{\circ} \mathrm{F}$. By reference to the first column of Table 4, it may be seen that the probability of this happening is nil. In fact, the maximum deviation if all the factors are a maximum is only $190^{\circ} \mathrm{F}$. For the second case, an additional $75^{\circ} \mathrm{F}$ must be added for the effect of the empty channel, and the resulting maximum local temperature is $1620^{\circ} \mathrm{F}$. The allowance for hot-channel factors is then $180^{\circ} \mathrm{F}$. By reference now to the second column of Table 4, it may be seen that the probability of exceeding $1800^{\circ} \mathrm{F}$ is 0.00093 . Since the factors in the second column of Table 4 were calculated for a $10 \%$ increase in power, the 0.00093 factor is slightly large. The maximum number of elements in any channel which may experience these temperatures is 14, and there are only four channels which receive this additional heat. The maximum number of elements to which this probability can be applied is 56 and the probability of one failure is $0.00093 \times 56$, or 0.052 .

There is no reasonable method with which to predict failures from material defects or fabrication methods. The fuel element specifications call for extensive inspection and individual leak testing of all elements. Between 50 and 100 of the assemblies were fabricated to check out the procedures and techniques for assembling, inspecting, and leak testing.

\section{Acknowledgments}

The information contained in this report was drawn from the work of many members of the ORNL Reactor and Metals and Ceramics Divisions and the Allis-Chalmers Research and Development Group. The author wishes especially to acknowledge the work on the correl'ations and temperature. structure by M. E. Lackey and R. S. Holcomb, the ORNL experimental work by H. W. Hoffman, J. L. Wantland, W. J. Stelzman, F. E. Lynch, and G. J. Kidd, and the Allis-Chalmers experimental work by R. M. Higgins and W. H. Lrandall. 


\section{$\underline{\text { References }}$}

1. Oak Ridge National Laboratory, "The ORNL Gas-Cooled Reactor," USAEC Report ORNL-2500, April 1, 1958.

2. Oak Ridge National Laboratory, "The ORNL Gas-Cooled Reactor, Materials and Hazards," USAEC Report ORNL-2505 (Rev. ), April 1, 1958.

3. Oak Ridge National Laboratory, "The ORIVL Gas-Cooled Reactor, Advanced Concepts," USAEC Report ORNL-2510, Sept. 18, 1958.

4. Oak Ridge National Laboratory, "GCRP Quar. Prog. Rep. June 30, 1960," USAEC Report ORNL-2964, pp. 84-86.

5. J. L. Wantland and R. L. Miller, "Heat Transfer in Septafoil Geometries by Mass-Trans Per Measurements," USACC Report ORNL-CF 59-6-9, Oak Ridge National Laboratory, June 30, 1959.

6. Oak Ridge National Laboratory, "GCRP Quar. Prog. Rep. June 30, 1960," USAEC Report ORNL-2964, pp. 59-67.

7. Oak Ridge National Laboratory, "GCRP Quar. Prog. Rep. Sept. 30, 1960," USAEC . Report ORNL-3015, pp. 53-63.

8. Oak Ridge National Laboratory, "GCRP Quar. Prog. Rep. June 30, 1960," USAE'C Keport URIVIL-296̈4, pN. 67-80.

9. Oak Ridge National Laboratory, "GCRP Quar. Prog. Rep. Sept. 30, 1960," USAEC Report, ORNT.-3015, pp. 63-67.

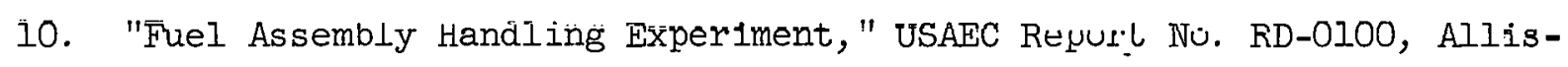
Chalmers Maruracturing Co.

11. T. K. DeBoer, "Calculation of Radial Neutron-Flux Distribution in EGCR Lattice Cell," USAEC Report ORNL-CF 59-8-140, Oak Ridge National Laborațory, Aug. 31, 1959.

12. C. A. Preskitt, "Suggested Operating Program for EGCR Control Rods," USAEC Report ORNL-CF 60-8-47, Oak Ridge National Laboratory, Aug. 8, 1960.

13. L. V. Humble, W. H. Lowdermilk, and L. G. Desmon, "Measurements of Average Heat Transfer and Friction Coefficients for Subsonic Flow of Air in Smooth Tubes at High Surface and Fluid Temperatures," National Advisory Committee for Aeronautics Report 1020, I951. 
14. M. E. Davenport and P. M. Magee, "Heat Transfer to a Gas at High Temperature," Technical Report No. 247-1, May 1960, Nuclear Technology Laboratory, Stanford University.

15. J. Hilsenrath and Y. S. Touloukian, "The Viscosity, Thermal Conductivity, and Prandtl Number for Air, $\mathrm{O}_{2}, \mathrm{~N}_{2}, \mathrm{NO}, \mathrm{H}_{2}, \mathrm{CO}, \mathrm{H}_{2} \mathrm{O}, \mathrm{He}$, and A," Trans. ASME, 74: 967 (1954).

16. F. G. Keyes, "The Heat Conductivity, Viscosity, Specific Heat, and PrandtI Number for Thirteen Gases, Project Squid," USAEC Report NP-4627 (1952).

17. J. B. Mann and N. C. Blais, "Thermal Conductivity of Helium and Hydrogen at High Temperature," USAEC Report LA-2316, Los Alamos Scientific Laboratory, September 1959.

18. M. P. Wilson, "Thermodynamic and Transport Properties of Helium,"

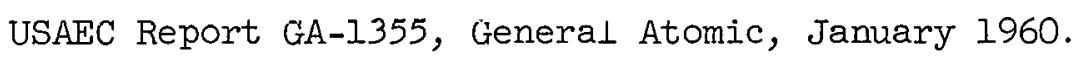

19. A. W. Nicklin, "The Thermal Properties of Carbon Dioxide, Nitrogen, Air, Hydrogen, and Helium," United Kingdom Atomic Energy Authority Report TN-36, 1956.

20. M. F. Taylor and A. Kirchgessner, "Measurements of Heat Transfer and Friction Coefficients for Helium Flowing in a Tube at Surface Temperatures Up to $5900^{\circ} \mathrm{R}$, " USAEC Report NASA-TN-D-133, National Aeronautics and space Administration, October 1959.

21. T. B. Fowler and E. R. Volk, "Generalized Heat Conduction Code for the IBM-704 Computer," USAEC Report ORNL-2734, Oak Ridge National Laboratory, October 1959.

22. I. G. Epel, "Numerical Three Dimensional Temperature Analysis of the EGCR Fuel Rod," USAEC Report ORIL-CF 60-3-1, Oak Ridge National Laboratory, March 27, 1960.

23. I. G. Epel, "Radiative Heat Transfer in Multisurfaced Nonblack Enulusures with Application to the EGCR Fuel Bundle," USAEC Report ORNL-CF 60-7-71, Oak Ridge National Laboratory, July 22, 1960.

24. J. M. Corum and W. A. Shaw, "Restrained Thermal Bowing of Beams Accompanied by Creep - With Application to the Experimental Gas-Cooled Reactor Fuel Elements," USAEC Report ORNL-CF 60-9-1, Oak Ridge National Laboratory, Dec. 6, 1960. 
25. Oak Ridge National Laboratory, "GCRP Quar. Prog. Rep. March 31, 1960," USAEC Report ORIL-2929, pp. 27-38.

26. G. Samuels, "Fuel Elements for Gas-Cooled Reactors," Monograph No. 7, Journal of the Franklin Institute, May 1960.

27. F. H. Abernathy, "The Statistical Aspects of Nuclear Reactor Fuel Element Temperature," USAEC Report ORNL-CF 60-7-31, Oak Ridge National Laboratory, July 13, 1960.

28. J. L. Scott, "Analys is of ORNL Data on the Release of Fission Gases from UO $\mathrm{U}_{2}$, USAEC Report ORNL-CF 60-8-15, Oak Ridge National Laboratory, Sept. 15, 1960.

29. M. W. Rosenthal, "PANDORA - A Computer Program for Estimating Fission-Gas Release and Its Effect on the Mechanical Life of Clad Fuel Elements," USAEC Report ORNL-CF 60-5-1, Oak Ridge National Laboratory.

30. "Experimental Gas-Cooled Reactor Preliminary Hazards Summary Report," USAEC Report ORO-196, May 1959.

31. J. C. Hedge and I. B. Fieldhouse, "Measurement of Thermal Conductivity of Uranium Oxide," Armour Research Foundation Report G022D3 (1956).

32. Oak Ridge National Laboratory, "GCRP Quar. Prog. Rep. Dec. 31, 1959," USAEC Report ORNL-2888, p. 78. 
ORNL-3478

UC-80 - Reactor Technology
TID-4500 (2lst ed.)

\section{Internal Distribution}

$\begin{array}{ll}\text { 1. } & \text { C. D. Baumann } \\ 2 . & \text { S. E. Beall } \\ 3 . & \text { E. J. Breeding } \\ 4 . & \text { R. D. Cheverton } \\ 5 . & \text { H. C. Claiborne } \\ \text { 6. } & \text { W. G. Cobb } \\ 7 . & \text { W. H. Cook } \\ \text { 8. } & \text { W. B. Cottrell } \\ 9 . & \text { D. R. Cuneo } \\ 10 . & \text { I. T. Dudley } \\ 11 . & \text { W. S. Ernst, Jr. } \\ 12 . & \text { A. P. Fraas } \\ 13 . & \text { W. R. Gall } \\ 14 . & \text { A. Goldman } \\ 15 . & \text { Neil Hilvety } \\ 16 . & \text { H. W. Hoffman } \\ 17 . & \text { J. O. Kolb } \\ 18 . & \text { A. L. Lotts } \\ 19 . & \text { H. G. MacPherson } \\ 20 . & \text { A. P. Malinauskas } \\ \text { 210. } & \text { W. D. Manly } \\ 41 . & \text { W. R. Martin } \\ 42 . & \text { H. C. McCurdy } \\ 43 . & \text { D. L. McElroy } \\ 44 . & \text { H. A. McLain } \\ 45 . & \text { T. R. McQuilkin } \\ 46 . & \text { S. E. Moore } \\ 47 . & \text { J. F. Murdock } \\ 48 . & \text { F. H. Neill } \\ & \end{array}$

49. Harry G. O'Brien

50. M. F. Osborne

51. A. M. Perry

52. J. J. Pinajian

53. C. A. Preskitt

54. S. A. Rabin

55. P. E. Reagan

56. M. W. Rosenthal

57. T. H. ROW

58-67. G. Samuels

68. H. W. Savage

69. Ann Savolainen

70. L. D. Schaffer

71. J. L. Scott

72. R. L. Senn

73. O. Sisman

74. M. J. Skinner

75. G. M. Slaughter

76. I. Spiewak

77. W. J. Stelzman

78. D. G. Thomas

79. G. M. Tolson

80. D. B. Trauger

81. J. T. Venard

82. J. L. Wantland

83. J. R. Weir

84-86. Central Research Library

87-89. Document Reference Library

90-114. Laboratory Records Department

115. Laboratory Records, R.C.

External Distribution

116-118. P. D. Bush, Kaiser Engineers

119. R. A. Charpie, UCC Research Administration, New York, N.Y.

120. W. R. Cooper, Tennessee Valley Authority

121-122. David F. Cope, Reactor Division, AEC, ORO

123-124. R. W. Coyle, Vallecitos Atomic Laboratory

125. L. L'rèutz, lienèéral Atomıc

126-128. R. B. Duffield, General Atomic

129. H. L. Falkenberry, Tennessee Valley Authority

130. D. H. Fax, Westinghouse Atomic Fower IIvision 
131. M. Janes, National Carbon Research Laboratories, Cleveland, Ohio

132. T. Jarvis, Ford Instrument Co.

133. James R. Johnson, Minnesota Mining and Manufacturing Company, Saint Paul, Minn.

134. Richard Kirkpatrick, AEC, Washington

135. C. W. Kuhlman, United Nuclear Corp.

136-137. H. Lichtenburger, General Nuclear Engineering Corp.

138-140. S. Matovich, Allis-Chalmers Mfg. Co.

141. J. P. McGee, Bureau of Mines, Appalachian Experiment Station

142. R. W. McNamee, Manager, UCC Research Administration, New York, N.Y.

143. S. G. Nordlinger, AEC, Washington

144. R. E. Pahler, High-Temperature Reactor Branch, Reactor Division, AEC, Washington

145. H. B. Rahner, Savannah River Operations Office

146. Corwin Rickard, General Atomic

147. M. T. Simnad, General Atomic

148. Nathanial Stetson, Savannah River Operations Of't'ice

149. Donald Stewart, AEC, Washington

150. Philip L. Walker, Pennsylvania State University

1.51. R. F. Watt, Los Alamos Scientific Laboratory

152-153. W. L. Webb, East Central Nuclear Group, Inc.

154. C. E. Winters, UCC, Cleveland, Ohio

155. Lloyd R. Zumwalt, General. Atomic

156. Division of Research and Development, $\mathrm{AEC}$, ORO

157-769. Given distribution as shown in TID-4500 (2lst ed.) under Reactor Technology category (75 copies - OTS) 